\title{
DUCTILE-TO-BRITTLE TRANSITION IN STEEL WELDMENTS FOR ARCTIC STRUCTURES
}

\author{
F. Zia-Ebrahimi
}

National Bureau of Standards

U.S. Department of Commerce

Boulder, Colorado 80303

April 1985 

NBSIR $85-3020$

\title{
DUCTILE-TO-BRITTLE TRANSITION IN STEEL WELDMENTS FOR ARCTIC STRUCTURES
}

\author{
F. Zia-Ebrahimi
}

Fracture and Deformation Division Center for Materials Science National Bureau of Standards U.S. Department of Commerce Boulder, Colorado 80303

April 1985

Sponsored by:

U.S. Department of Interior Minerals Management Service 12203 Sunrise Valley Drive

Reston, Virginia 22091

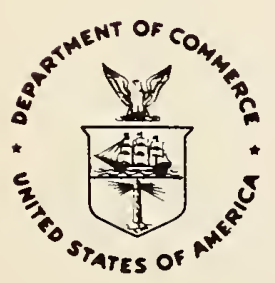

U.S. DEPARTMENT OF COMMERCE, Malcolm Baldrige, Secretary 

1. Introduction

2. Material and Experimental

Procedures

2.1 Test Material

2.2 Tensile Testing

2.3 Charpy V-Notch Testing

2.4 COD Testing

2.5 Microscopy

3. Results

3.1 Optical Microscopy

3.2 Tensile Properties

3.3 Impact Toughness

3.4 Fracture Toughness

3.5 Fractography.

3.5.1 SENB Specimens

3.5.2 CVN Specimens

4. Comparison With Base Metal Properties

4.1 Tensile Properties

4.3 Fracture Toughness

5. Discussion

6. Summary and Conclusions

7. References 

DUCTILE-TO-BRITTLE TRANSITION IN STEEL WELDMENTS FOR ARCTIC STRUCTURES

\author{
F. Zia-Ebrahimi \\ Fracture and Deformation Division \\ National Bureau of Standards \\ Boulder, Colorado 80303
}

This report summarizes the work performed in support of the development of fracture criteria for steel weldments in arctic structures. The ductileto-brittle transition behavior of a shielded metal-arc weld, typical of steel weldments in arctic structures, has been studied. Fracture toughness, Charpy V-notch impact energy, and tensile properties have been measured as a function of temperature throughout the ductile-to-brittle transition range. The effect of geometric dimensions on fracture toughness has been studied for three geometries of single-edge-notch-bend (SENB) specimens. The fracture surfaces of broken specimens have been characterized by scanning electron microscopy (SEM). The microstructure of the multiple-pass weldment has been studied by optical microscopy. The mechanical properties of the steel weldment have been compared to the base metal, an ABS grade EH36 steel in normalized condition. The results indicate that the resistance to brittle fracture is the same in both the base metal and the weld metal; however, the weld metal has a much lower resistance to ductile fracture than the base metal does. The high ductile-to-brittle transition temperature of the weld metal is attributed to its high tensile strength and low resistance to ductile fracture.

The ductile-to-brittle transition temperature increased by $25^{\circ} \mathrm{C}$ with increasing specimen thickness (from $12.7 \mathrm{~mm}$ to $25.4 \mathrm{~mm}$ ), an effect that can be 
attributed to both the constraint and statistical effects. The slight increase in ductile-to-brittle transition temperature with increasing crack length/specimen width ratio is discussed on the basis of constraint effects. The SEM fractography revealed a shear zone preceding the unstable brittle fracture in SENB specimens tested in the transition temperature regime. This finding shows that the fracture initiation process in these specimens is controlled by ductile fracture rather than brittle fracture, although no macroscopic slow crack growth was observed.

Key words: crack initiation; fracture toughness; fracture surface; microstructure; 3-point band tests; transition temperature; weldments 


\section{Introduction}

The reliability and overall safety of a structure depend on all phases of design, fabrication, quality control, and inspection, by which a fractureresistant structure is constructed. Fracture mechanics is a tool to translate the results of fracture toughness testing into engineering design. Although, many recently developed structural codes and specifications that have material toughness requirements are based on fracture mechanics principles, the toughness tests specified for material purchase or quality control are in terms of simple tests, such as the Charpy V-notch (CVN) test. The inadequacy of CVN testing for evaluation of the fracture toughness of steel weldments in arctic structures and the need for development of more satisfactory fracture criteria have been discussed elsewhere $[1,2]$.

Since the results of fracture toughness testing are obtained in the presence of a notch or some other form of stress raiser, knowledge of the precise magnitudes and distribution of stresses and strains near the stress concentrator is essential. To correlate the results of fracture toughness testing with a parameter that represents a material property, a fracture criterion should be established. Theoretically, the problem of stresses and strains ahead of a crack has been solved for small-scale yielding and fully plastic cases for either plane-strain or plane-stress conditions. No theoretical solution is available for situations where the amount of plastic deformation at the crack tip is between small-scale yielding and general yielding, and where the stress state is a mixed condition of plane-strain and planestress conditions. As far as the fracture criteria for various modes of fracture are concerned, it is commonly assumed that brittle fracture occurs 
when a critical fracture stress is achieved ahead of the crack tip (stresscontrolled fracture) and that ductile fracture occurs when a critical fracture strain is obtained ahead of the crack tip (strain-controlled fracture) [3].

In general, unstable fracture occurs when the driving force for crack extension exceeds the material's resistance to fracture. Under small-scaleyielding conditions, the driving force for extension of a stationary crack can be related to the crack-tip stress intensity factor, $K$. Unstable fracture occurs when the stress intensity factor reaches its critical value, $\mathrm{K}_{c}$, which is a measure of the fracture toughness of the material. Linear-elasticfracture mechanics (LEFM) provides the relationship between $\mathrm{K}$ and macroscopically measurable parameters, namely applied stress and crack length, for plane-strain and plane-stress deformation conditions at the crack tip. Plane-strain fracture toughness, $\mathrm{K}_{\mathrm{Ic}}$, testing (ASTM E-399) has been designed to measure the toughness of a material under small-scale-yielding and planestrain conditions where principles of LEFM are valid. These conditions are achieved through specimen size restrictions in the $\mathrm{K}_{\mathrm{Ic}}$ test method. The fracture criterion defined by plane-strain fracture toughness testing is geometry independent and, therefore, the $\mathrm{K}_{\mathrm{Ic}}$ value is a material property. However, plane-strain fracture toughness is a conservative measure of fracture toughness of a material and for laboratory-size specimens the applicability of the $\mathrm{K}_{\mathrm{Ic}}$ test method is limited to relatively brittle structural materials, to low testing temperatures that are below normal service temperature, or to very high rates of loading.

In the absence of sufficient constraint at the crack tip, stable or slow crack growth may occur in relatively high-toughness materials. The R-curve testing method (ASTM E-561) has been designed to characterize the resistance of cracked thin metal sheets to stable crack growth under small-scale 
yielding. Under limiting conditions of plane stress or plane strain, the increase in crack length, $\Delta \mathrm{a}$, has a unique functional relationship to the stress intensity factor, $K$. If fracture, stable or unstable, occurs under a mixed condition of plane strain and plane stress, the stress state ahead of the crack is complex and a single parameter, $\mathrm{K}$, cannot characterize the stress distribution. The complexity increases when crack extension occurs under large-scale yielding, i.e., the size of the plastic zone at the crack tip becomes comparable to specimen and/or crack size. Under the above conditions the behavior of the material is referred to as elastic-plastic where the simple functional relationship between the stress intensity factor and the driving force for crack extension breaks down. The J-integral (ASTM E-813) and crack-opening displacement (COD) (BS 5762) testing methods have been designed on the basis of elastic-plastic fracture mechanics (EPFM). Unfortunately, in this regime there is no geometry-independent fracture toughness parameter, and both $\mathrm{J}_{\mathrm{Ic}_{\mathrm{c}}}$ and critical crack-tip opening displacement (CTOD), $\delta_{c}$, decrease with an increase in specimen size $[1,2,4,5]$. Therefore, the laboratory specimens should be designed to have plastic constraint similar to the structural component. For example the COD testing method requires the thickness, $B$, of the specimen to be equal to that of the material under examination.

The different failure paths that generally a cracked body can follow, are summarized in figure 1 [6]. For a particular material, the change in failure path from 1 to 5 can be associated with an increase in test temperature for a constant specimen geometry and/or a decrease in geometric dimensions, such as specimen thickness and crack length, and an increase in notch root radius for a constant test temperature. The variation of fracture behavior with test 
temperature has been traditionally characterized by ductile-to-brittle transition curves. It is well known that in body-centered cubic (bcc) metals toughness and ductility increase with increasing temperature, and the fracture mode changes from brittle at low temperature to ductile at high temperature. This transition, which is a consequence of the temperature dependence of flow stress, the temperature independence of the cleavage fracture, and the associated notch sensitivity, was first explained by Orowan [7]. In general, there is a competition between ductile and brittle types of fracture. At a particular temperature, a variation in parameters that change stress and strain distributions (such as loading mode, deformation rate, and geometry) may promote either of the fracture modes.

Most models for explaining ductile-to-brittle transitions are based on the change in constraint at the crack tip. Recent studies $[5,6,8,9]$ have shown that plane strain fracture toughness, $\mathrm{K}_{\mathrm{Ic}}$, also reflects a ductile-tobrittle transition. The transition is associated with a change in mode of fracture from brittle cleavage to fast ductile. Note that in the abovementioned investigations the size of the specimen has been increased with an increase in test temperature in order to obtain ductile fracture under plane strain and small-scale yielding conditions. For common specimen sizes most experimental data available show that general yielding occurs before ductile fracture initiation, and therefore one of the elastic-plastic techniques, such as COD testing, should be applied to measure the fracture toughness. The various regimes of fracture and deformation behavior throughout the ductile-to-brittle transition temperature range are summarized in figure 2. The fracture behavior can be categorized on the basis of (a) general yielding, (b) stress state, or (c) mode of crack initiation and propagation. Whereas (a) and (b) define the stresses and strains ahead of a 
crack at the time of the fracture event, the fracture mode of crack initiation and propagation, (c), defines the fracture criterion. The shape and temperature range of the ductile-to-brittle transition curve and the position of the boundaries of the above-mentioned fracture behavior categories are expected to depend on material properties (such as yield strength, work-hardening behavior, and fracture stress), and specimen geometry.

The purpose of this investigation is to study the ductile-to-brittle transition behavior of a shielded metal-arc weld, a typical weldment in arctic structures. Fracture toughness was measured by the COD testing method at temperatures throughout the ductile-to-brittle transition. The effect of geometric dimensions on fracture toughness was studied by changing the crack length to specimen width ratio $(a / W)$ and the thickness of SENB specimens. Emphasis was placed on mechanisms of crack initiation as characterized by detailed fractography.

\section{Materials and Experimental Procedures}

\subsection{Test Material}

The base material is a 25.4-mm-thick plate of ABS grade EH36 steel, composition of which is given in reference 1. A manual shielded metal-arc welding process with 8018-C3 electrode was chosen as a typical welding practice for structural assemblies. The welding procedure specifications are summarized in table 1. Specimens for tensile, CVN, and COD testing were machined from the welded plate with the length and notch orientation as shown schematically in figure 3.

\section{$\underline{2.2}$ Tensile Testing}

Round tensile specimens with a reduced cross section, as shown in 
figure 4, were tested at various temperatures ranging from $-258^{\circ} \mathrm{C}$ to $25^{\circ} \mathrm{C}$. This specimen geometry was used to enable tensile property measurement of just the weld metal. Tensile tests were conducted in a screw-driven tensile test machine equipped with a fixture designed for cryogenic testing at a crosshead speed of $0.5 \mathrm{~mm} / \mathrm{min}$. Owing to the short gage length of these specimens the strain could not be recorded directly with an extensometer. Therefore, a calibration curve of uniform plastic strain versus time was established by loading single tensile specimens at room temperature to various uniform strain levels and measuring a premarked gage length of $12.7 \mathrm{~mm}$ in a traveling microscope with an accuracy of $\pm 0.001 \mathrm{~mm}$. This calibration curve was used to calculate the maximum uniform strain. The total elongation was obtained by measuring the premarked gage length after the fracture of the actual tensile specimen .

\subsection{Charpy V-Notch Testing}

Standard Charpy V-notch specimens were tested in a machine with a fullscale energy value of $358 \mathrm{~J}$. Testing was performed in the temperature range $-94^{\circ} \mathrm{C}$ to $+94^{\circ} \mathrm{C}$ according to the ASTM-E23 standard for impact testing. Specimens were placed in a constant temperature bath (oil for temperatures above RT and methanol for temperatures below RT) for $15 \mathrm{~min}$ and tested within $7 \mathrm{~s}$ after removal from the bath. For each specimen the lateral expansion was measured according to ASTM standard A-370.

\subsection{COD Testing}

Three-point SENB specimens of constant width $(W=21.8 \mathrm{~mm})$ with various thicknessess, B, and crack length to width ratios, a/W, (see table 2) were prepared by fatigue precracking at room temperature according to the specifications in the British Standard for COD testing (BS 5762). The specimen geometry and the test procedure have been explained in detail elsewhere [1] and are not 
discussed here. The SENB specimens were tested in the temperature range $-196^{\circ} \mathrm{C}$ to $-45^{\circ} \mathrm{C}$, which resulted in critical CTOD values between $0.003 \mathrm{~mm}$ and $0.4 \mathrm{~mm}$ for establishing the ductile-to-brittle transition curves. For all the specimens tested, macroscopically, no stable crack extension was observed on the fracture surface. Therefore, according to the British Standard for COD testing (B55762) the notation for the CTOD values correspond to $\delta_{c}$, designating the unstable cleavage-no prior slow crack growth situation. However, as will be discussed later, ductile microcracking preceded brittle fracture in some of the specimens.

As noted in the Results Section (3.1), a ductile-to-brittle transition curve could not be obtained for specimens with $a / W=0.5$ because of weld defects located in the root of the weld.

The critical CTOD values were calculated from the following relationship:

$$
\delta=\delta_{e}+\delta_{p}=\frac{K^{2}\left(1-v^{2}\right)}{2 \sigma_{y} E}+\frac{r_{p}(W-a) v_{p}}{r_{p}(W-a)+a+Z}
$$

where: $\mathrm{K}$ = stress intensity factor

$$
\begin{aligned}
& \sigma_{y}=\text { yield strength } \\
& E=\text { Young's modulus } \\
& \nu=\text { Poisson's ratio } \\
& r_{p}=\text { rotational factor } \\
& V_{p}=\text { The plastic component of the mouth-opening displacement } \\
& Z=\text { knife edge thickness }
\end{aligned}
$$

The rotational factor, $r_{p}$, was calculated based on the relationship between the plastic components of load-line displacement and the mouth-opening displacement [10]. The computed rotational factor was found to change moderately with CTOD, and the average value close to the fracture events was 
approximately 0.4, the same value as suggested by the British Standard (BS 5762). 2.5 Microscopy

The fracture surfaces of the broken specimens were studied by using a scanning electron microscope. Emphasis was placed on characterization of the crack initiation zone in SENB specimens.

The microstructures resulting from the multiple-pass welding process and the position of the crack tip for SENB specimens relative to these microstructures were studied by optical microscopy.

\section{Results}

\subsection{Optical Microscopy}

Figure 5 shows a low magnification optical micrograph of the weld. Large globular porosities on the order of $0.5 \mathrm{~mm}$ in size can be seen at the root of the weld. These defects were large enough to cause a premature fracture of SENB specimens with $a / W=0.5$ geometry. The crack tip in these specimens was located close to the porosities, and as a result, plastic deformation became concentrated in the ligament between the crack tip and the nearest porosity. Stresses higher than what would be expected in a porosity-free specimen were produced in this ligament and caused a premature fracture, which was revealed as a pop-in on the load-displacement curve. Therefore, no meaningful fracture toughness data could be obtained for SENB specimens with $a / W=0.5$ geometry

Different weld passes can be identified in the micrograph shown in figure 5. Each inner pass contains two distinctive microstructures. One consists of elongated prior austenite grains delineated by allotriomorph ferrite that resulted from the solidification of the molten weld metal. The other consists of equiaxed prior austenite grains formed by reaustenitizing of the columnar microstructure due to the heat generated from the next weld pass. The latter 
microstructure can be viewed as the heat affected zone of one pass due to the following weld pass.

Figure 6 shows higher magnification micrographs of these two microstructures. The fracture toughnesses of the above-mentioned microstructures are significantly different. As shown in figure 5, the approximate position of the crack tip of specimens with both $a / W=0.25$ and $a / W=0.75$ is located in the microstructure with equiaxed grains.

\subsection{Tensile Properties}

The tensile properties of the weld metal are given in table 3 . The ultimate tensile strength and yield strength as a function of test temperature are plotted in figure 7 . The weld metal had a relatively high yield strength (550 $\mathrm{MPa}$ at room temperature), as is expected for E8018-C3 electrode [11]. Both the ultimate tensile strength and yield strength increased with decreasing test temperature. The effect of temperature on strength became more significant for test temperatures below $-100^{\circ} \mathrm{C}$. All the stress-strain curves showed some indication of yield elongation but did not exhibit an upper and lower yield point except for the specimen tested at $-196^{\circ} \mathrm{C}$. The increase in Luders strain and the difference between upper and lower yield point with a decrease in test temperature has been observed previously for bcc metals [12]. The maximum uniform strain did not change considerably with test temperature. The work hardening rate, as reflected by the difference between yield strength and ultimate tensile strength, decreased slightly with decreasing test temperature.

\subsection{Impact Toughness}

The CVN impact energy as a function of test temperature is shown in figure 8. The weld metal exhibited a very gradual ductile-to-brittle transition with a transition temperature range extending from $-100^{\circ} \mathrm{C}$ to $+100^{\circ} \mathrm{C}$. This wide transition temperature range was reflected in the gradual change in the amount of brittle, fibrous, and shear fracture observed on the fracture 
surfaces, as shown in figure 9. The Charpy V-notch data are also given in table 4.

\subsection{Fracture Toughness}

The COD test results for the weld metal are summarized in table 5 . The critical CTOD values for the geometries studied are shown as a function of test temperature in figure 10. As mentioned previously, due to weld defects located at the weld root, no meaningful data were obtained for specimens with $\mathrm{a} / \mathrm{W}=0.5$ geometry. Figure 10 shows that an increase in the specimen thickness from $12.7 \mathrm{~mm}$ to $25.4 \mathrm{~mm}$ raised the ductile-to-brittle transition temperature about $25^{\circ} \mathrm{C}$. The effect of an increase in the crack length to specimen width ratio, a/W, from 0.25 to 0.75 is revealed as a significant change in the shape of the ductile-to-brittle transition curve towards a much steeper slope with a slight shift to higher test temperatures. These observations are consistent with those made for the base metal [1,2], an ABS grade EH36 steel in normalized condition.

\subsection{Fractography}

\subsubsection{SENB Specimens}

Figures 11 and 12 show macrographs of the fracture surface for $B=25.4 \mathrm{~mm}$ and $B=12.7 \mathrm{~mm}$ geometries, respectively. For each geometry, macrographs of two specimens, one tested at $-196^{\circ} \mathrm{C}$ and the other tested at a temperature corresponding to $\delta_{c} \cong 0.35 \mathrm{~mm}$, are presented. The important feature of these macrographs is the relative amount of the slant or shear fracture on the sides of the specimen. When $\delta_{c}$ is as large as $0.35 \mathrm{~mm}$ for both thicknesses it can be seen that the amount of shear fracture is less than $10 \%$ of the total fracture surface. Therefore, it may be concluded that the specimens tested in this study deformed under conditions close to those of plane strain deformation and any difference in the behavior of the edges of the specimen is 
insignificant in determining failure conditions for the specimen as a whole. However, there has been concern whether a square fracture appearance is a definitive indication of plane-strain conditions [9].

The fracture surfaces of the SENB specimen tested in this study did not show any macroscopic slow crack growth preceding the unstable fracture. However, a ductile shear zone was revealed next to the fatigue precrack, preceding the unstable fracture, in most specimens. This shear zone should not be confused with the stretch zone, which is commonly reported in COD testing [13]. To clarify the various fracture zones observed on the fracture surface, the crack-tip blunting and the fracture process at the crack tip are discussed along with the presentation of fractographs.

As the load applied to a specimen containing a sharp crack is increased, a plastic zone develops at the crack tip. The crack tip becomes blunted and tends to be curved, as shown in figure 13b. Because of the Poisson's contraction of the material in the plastic zone, the crack has a forward movement [13]. The blunting of the crack tip is identified on the fracture surface as a stretch zone between the fatigue crack and the area of crack extension by cleavage or void formation. Figure 14 shows the featureless, amorphous appearance of the stretch zone. The large geometry change at the crack tip has been treated theoretically by modified slip-line field theory, as shown in figure $13 \mathrm{c}$. This method is justified for nonhardening materials and planestrain conditions [14]. The crack tip becomes similar to a circular notch as a result of the progressive blunting of the crack tip with deformation. Fracture is initiated by ductile or cleavage modes when the critical condition for the either of the modes is reached ahead of the crack tip. Hence, the micromechanism of the crack initiation process can be divided into two categories: (a) crack initiation by cleavage fracture and (b) crack initiation 
by ductile fracture. Within each category the crack can extend in various ways, as shown schematically in figures 15 and 16 . In the following, crack initiation and propagation mechanisms are discussed with respect to effects of temperature.

(a) Crack Initiation by Cleavage

In the lower-shelf temperature range, critical conditions for cleavage are reached under the situation of a small plastic zone and limited blunting at the crack tip. Assuming that cleavage is a stress-controlled fracture process, a cleavage microcrack forms when the maximum tensile stress ahead of the tip reaches the fracture stress, $\sigma_{f}^{*}[15,16]$. It has been suggested that the fracture stress should be reached over a characteristic distance ahead of the crack tip [17]. This characteristic distance is related to microstructural features that control the fracture, such as particle size and spacing and grain size. The cleavage microcrack may join the crack tip in two ways. At. very low temperatures, where the size of the ligament between the cleavage microcrack and the fatigue precrack is very small and the yield strength is high, the cleavage crack extends to the crack tip and no ductile fracture develops ( $\mathrm{fig}$. 15a). This behavior was observed for SENB specimens tested at $-196^{\circ} \mathrm{C}$, an example of which is shown in figure 17 . Note that the stretch zone in this case is very small $\left(\sim 1 / \sqrt{2} \delta_{c}=0.002 \mathrm{~mm}\right)$ and cannot be observed on this fractograph.

As the temperature is increased within the lower shelf energy range, owing to a significant drop in yield strength, critical fracture stress for cleavage is achieved at larger plastic zones accompanied by a larger stretch zone size than in the case discussed above. In this regime, cleavage cracks form only when a certain amount of strain hardening has occurred in the plastic zone. Therefore, strain becomes localized in the ligament between the 
cleavage microcrack and the fatigue crack, and the cleavage crack extends to the notch by a shear mechanism along the maximum shear stress planes predicted by slip-field theory $[18-20]$. As a result, a shear zone is formed by the ductile (microvoid coalescence) mode, which on the fracture surface precedes the unstable cleavage fracture (fig. 15b).

(b) Crack Initiation by Ductile Fracture

As the test temperature is raised into the ductile-to-brittle transition temperature range, a point will eventually be reached where the combination of stresses and strains ahead of the blunted crack favors the formation of ductile microcracks. If the stress intensification at the tip of the ductile microcrack is large enough, a cleavage fracture will be triggered (fig.16). In this case the fracture surface consists of fatigue precrack, stretch zone, shear zone, and the unstable cleavage crack, similar to the situation in figure 15b. However, there is a definite difference between these two cases. If the crack initiation occurs by cleavage microcracking, the shear zone size correlates with the size of the plastic zone along the crack front, i.e. It will be the smallest at the midthickness (plane strain) and the largest at the edges (plane stress). If the crack is initiated by ductile microcracking the shear zone has a thumbnail shape with its maximum size located at the midthickness. Figures 18 and 19 show this difference in the shear zone size for two SENB specimens. The smaller shear zone size in the midthickness in comparison to the edges is demonstrated in figure 18. Figure 19 shows that the shear zone attains its maximum size in the midthickness, an indication of crack initiation by ductile fracture. Macroscopically, in the shear zone the fracture surface is oriented $45^{\circ}$ from the direction of the maximum tensile stress developed by bending. Figure 20 illustrates the relative orientation 
of the stretch zone and the shear zone by tilting the specimen in the SEM by $45^{\circ}$ in two opposite directions.

If the stress intensification at the tip of the ductile microcrack is not large enough for initiation of a cleavage crack, the crack will extend by fibrous mode. This slow crack growth may change to an unstable fracture or it may extend until complete fracture of the specimen.

As was mentioned in Section 3.1, the two distinct microstructures shown in figure 6 have a significantly different toughness. This difference in toughness was well demonstrated for one of the SENB specimens where the crack front was located in both microstructures. The load-displacement curve for this specimen was characterized by a pop-in that correlated with cleavage fracture along a portion of the thickness, as marked by letter A in figure 21a. Figure $21 \mathrm{~b}$ shows a low magnification SEM fractograph of the boundary between the area that fractured first, $A$, and the area that fractured after the arrest of the first crack, B. Note the large shear zone in the latter area. Figure 22 shows SEM fractographs of the brittle crack in both areas. In area $B$ the small cleavage facets correspond to the small equiaxed grains shown in figure 6. In area A the crack has followed the large proeutectoid ferrite grains ( $\alpha$-veins; see fig. 6), as illustrated by the large columnar cleavage facets shown in figure $22 \mathrm{a}$.

\subsubsection{CVN Specimens}

In general, the crack initiation process in CVN specimens is very similar to what was discussed in the preceding section $[19,20]$ except for effects of notch geometry. Figure 23 shows a low magnification SEM fractograph of the CVN specimen tested at $-73^{\circ} \mathrm{C}$. A large shear zone next to the notch shows that fracture was initiated by ductile fracture in this specimen. It has been shown 
that most of the energy measured for fracture of CVN specimens is absorbed during the process of deformation and development of this shear zone [21].

\section{Comparison with Base Metal Properties}

In this section, the properties of the base metal, an ABS grade EH36 steel, and the weld metal, obtained by manual metal-arc welding process with 8018-C3 electrode in accordance with table 1 specifications, are compared. The base metal properties have been reported in references 1 and 2 .

\subsection{Tensile Properties}

In the temperature range $-196^{\circ} \mathrm{C}$ to $25^{\circ} \mathrm{C}$, the weld metal and base metal show a similar decrease in strength with an increase in test temperature. The strength of the weld metal, on the the average, is about $200 \mathrm{MPa}$ higher than the base metal. The base metal has, in general, a larger total elongation than does the weld metal. The well-defined upper and lower yield point observed in the base metal were not exhibited by the weld metal. The absence of yield elongation in the weld metal may be attributed to higher cooling rates and presence of residual stresses in the weld metal. The fracture stress for the weld metal obtained from low temperature tensile tests is 1170 $\mathrm{MPa}$, which is very close to the $1156 \mathrm{MPa}$ value reported for the base metal [2].

\subsection{Impact Toughness}

Figure 24 shows the ductile-to-brittle transition curve for both the base metal and the weld metal. The weld metal has a much lower upper shelf energy with a very wide transition temperature range. Note that the lower shelf energy level is the same for both materials, consistent with the similarity in their fracture stress values. The low resistance to ductile fracture of the weld metal could be due to the high density of relatively fine inclusions and carbide precipitates in the weld metal microstructure (see fig. 6). The low 
resistance to ductile fracture of the weld metal is manifested not only by the low upper shelf energy but also by the shallow slope of the ductile-to-brittle transition curve. For the base metal, the difference between the resistance to brittle fracture and ductile fracture is so large that complete fracture of the specimen occurs by either ductile or brittle fracture. The large scatter in fracture toughness data usually observed for materials with a very narrow ductile-to-brittle transition range is due to the statistical effects of microstructure. For example, in the vicinity of the transition temperature of the base metal, a specimen will break with a low absorbed energy if there is a microstructural feature, such as carbides, positioned in a way that can trigger cleavage fracture. On the other hand, if the crack starts in a ductile mode, the stress level ahead of the ductile crack will never be high enough to change to a brittle fracture mode. In comparison, a ductile crack in the weld metal can develop under small deformation at the notch. The degree of crack blunting at the tip of the ductile crack will be less than the case for the base metal. Furthermore, the weld metal has a higher strength level than the base metal does, while the fracture stress is the same. Therefore, the ductile crack in the weld metal can change to an unstable brittle fracture, which results in a wide range of absorbed energy and hence a less steep ductile-to-brittle transition curve.

\subsection{Fracture Toughness}

The weld metal and the base metal exhibited the same $\mathrm{K}_{\mathrm{Ic}}$ value of $37 \mathrm{MPa} \sqrt{\mathrm{m}}$ when tested at $-196^{\circ} \mathrm{C}$, which is consistent with the previously mentioned observations, i.e., similar fracture stress and lower shelf impact energy. As far as the effect of specimen thickness and crack length to specimen width ratio on the transition curve is concerned, the weld metal and the base metal showed the same behavior. The fracture toughness transition temperature for 
the weld metal is about $50^{\circ} \mathrm{C}$ higher than for the base metal, while the slope of the transition curve is the same in both the weld metal and the base metal as shown in figures 25 and 26 for two different geometries. The latter observation is quite different from the CVN impact data, which exhibited a significant difference in slope between the weld metal and the base metal.

The inconsistency between the results of Charpy impact and fracture toughness testing has been explained by the more complex nature of the fracture process associated with CVN testing [21]. The total CVN impact energy in the ductile-to-brittle transition temperature range is subdivided into components associated with energy absorbed during initiation and formation of the shear zone, energy absorbed during fibrous fracture, and energy absorbed after the arrest of the unstable crack [20,21]. Instrumented Charpy impact testing provides information with which the above energy components can be measured $[20,21]$. The critical CTOD data are expected to correlate better with the energy component absorbed during initiation and formation of the shear zone in CVN specimens than with the total CVN energy. The other important factor contributing to this inconsistency is the inhomogenity of microstructure in the weld metal. The total impact energy is an average of the energy components absorbed during the processes of initiation and propagation of both ductile and brittle fracture in various microstructures of the weld metal. Furthermore, there are differences in crack geometry and loading rate between the Charpy impact and the COD tests that contribute to the dissimilarity in the results obtained by the two test methods.

\section{Discussion}

In this section, the effects of material properties and specimen geometry on the ductile-to-brittle transition temperature are discussed. There have 
been many definitions for the ductile-to-brittle transition temperature. The most common definition is the temperature, $\mathrm{T}_{\mathrm{GY}}$, at which fracture occurs at the general yielding point defined as net section yielding [12]. This temperature is marked by an arrow in figures 10, 25, and 26. For the limited data available in the present investigation, this definition of the ductile-tobrittle transition temperature seems to be appropriate.

The load at general yielding for the specimen geometry used in this study is given by:

$$
P_{G Y}=L \frac{\sigma_{y}(W-a)^{2} B}{4 W}
$$

where $L$ is referred to as the global constraint factor. The fracture load is calculated from the following expression:

$$
P_{F}=\frac{K_{c} W^{\frac{1}{2}} B}{Y}=\frac{\left(m \delta{ }_{c} \sigma_{y} E\right)^{\frac{1}{2}} W^{\frac{1}{2}} B}{Y}
$$

where: $Y=$ stress intensity coefficient $=Y(a / W)$

$$
\mathrm{m}=2 /\left(1-v^{2}\right) \text { plane strain }
$$

$$
\mathrm{m}=1 \text { plane stress }
$$

Equating $P_{F}=P_{G Y}$ results in:

$$
\frac{1}{\delta_{c}} \quad \frac{\sigma_{y}}{E}=\frac{16 m}{L^{2} W(1-a / W)^{4} Y^{2}} \text { at } T_{G Y}=T
$$

To predict the ductile-to-brittle transition temperature for a particular specimen geometry, assumptions have to be made about the deformation condition 
at the crack tip (plane strain vs. plane stress), which establishes the values of $\mathrm{m}$ and $\mathrm{L}$, and a criterion for fracture, which establishes $\delta_{c}=\delta_{c}(\mathrm{~T})$. If $\sigma_{y}$ and $E$ as a function of temperature are known, then the temperature $T_{G Y} c a n$ be calculated from eq (4). Unfortunately, both the deformation condition at the crack tip and the fracture criterion may change through the ductile-tobrittle transition temperature range, which adds to the complexity of the problem.

Based on the above discussion, the first step to be taken in explaining the effects of material and specimen geometry on the ductile-to-brittle transition temperature is to make assumptions about stress state and mode of crack initiation at $\mathrm{T}_{G Y}$. As far as the criterion for fracture is concerned, for the three SENB geometries of the weld metal tested, at $\mathrm{T}_{G Y}$ the crack has been initiated by cleavage. This conclusion is based on detailed fractogrpahy performed on the specimens (see section 3.5.1). It should be noted that this conclusion is valid only for the specimen geometries tested here. For large engineering structures it is very likely that ductile fracture can be started at load levels much below the general yield load. The presence of less than $5 \%$ shear lips on the fracture surface of SENB specimens tested at $T_{G Y}$ suggests that crack initiation and propagation occurred under plane strain conditions in these specimens. Such a conclusion may not be strictly correct, and there is the possibility that square fracture can extend under a mixed mode.

Since both the weld metal and the base metal have the same microscopic fracture stress, $\sigma_{f} *$, the $50^{\circ} \mathrm{C}$ difference in their transition temperature for a given geometry (see figs. 25 and 26 ) should be related to the difference in their yield strength. Assuming plane strain conditions for the deformation near the crack tip and brittle fracture as the mode of crack initiation, it can be shown that [22]: 


$$
\sec \left(\frac{\pi}{2} \frac{\sigma_{F}}{\sigma_{G Y}}\right)-1=g \exp \left(\frac{\sigma_{\mathrm{f}}^{*}}{\sigma_{\mathrm{y}}}-1\right)-1
$$

where $\sigma_{F}$ and $\sigma_{G Y}$ are the nominal stresses at the fracture and general yielding point, respectively, and $g$ is a parameter that accounts for finite specimen and crack geometry. Equation (5) has been derived by equating the plastic zone size of the Dugdale model to the plastic zone size of the slip-field theory at the point of the fracture. Equation (5) implies that for a given specimen geometry equivalent values of $\sigma_{F} / \sigma_{G Y}$ lead to equivalent values of $\sigma_{f}^{*} / \sigma_{y}$. Therefore, for a constant $\sigma_{F} / \sigma_{G Y}$ ratio, as arbitrarily chosen for the definition of the transition temperature:

$$
\frac{\sigma_{f}^{*}}{\sigma_{G Y}}=\text { constant }
$$

or

$$
\frac{\sigma_{f}^{*}}{\sigma_{y}}\left(\text { material 1) }=\frac{\sigma_{f}^{*}}{\sigma_{y}}\right. \text { (material 2) }
$$

For the base metal and the weld metal:

$$
\sigma_{f}^{*}(1)=\sigma_{f}^{*}(2) \cong 1160 \mathrm{MPa}
$$

Therefore:

$$
\sigma_{\mathrm{y}}(1)=\sigma_{\mathrm{y}}(2)
$$

For the $B=25.4 \mathrm{~mm}$ and $\mathrm{a} / \mathrm{W}=0.25$ specimen geometry of the weld metal, $\sigma_{\mathrm{y}}$ $\left(\mathrm{T}_{G Y}=-83^{\circ} \mathrm{C}\right)=590 \mathrm{MPa}$. The temperature at which the yield strength of the 
base metal is equal to $590 \mathrm{MPa}$ is $-132^{\circ} \mathrm{C}$ [2]. For the $\mathrm{B}=12.7 \mathrm{~mm}$ and a $/ \mathrm{W}=$ 0.25 geometry for the weld metal $\sigma_{y}=640 \mathrm{MPa}$ at $\mathrm{T}_{\mathrm{GY}}=-108^{\circ} \mathrm{C}$, which leads to a $\mathrm{T}_{G Y}$ of $-150^{\circ} \mathrm{C}$ for the base metal. The transition temperature shifts of $49^{\circ} \mathrm{C}$ and $42^{\circ} \mathrm{C}$ predicted for $\mathrm{B}=25.4 \mathrm{~mm}$ and $\mathrm{B}=12.7 \mathrm{~mm}$ specimen geometries correlate surprisingly well with the experimental results.

For SENB specimens with load span of $4 \mathrm{~W}$, the parameter $\mathrm{g}$ in eq (5) is given by the following expression [22]:

$$
g=\frac{12 \pi^{3}}{w(1-a / w)^{4} y^{2}} \rho
$$

where $\rho$ is the notch root radius. In the case of sharp cracks, $\rho$ becomes $\rho_{0}$, which is a microstructural characteristic distance [24]. For a constant specimen width, an increase in the a/w ratio decreases $(1-a / w){ }^{4} y^{2}$, which leads to a larger $\sigma_{y}$, according to eq (5). Consequently, a decrease in transition temperature with an increase in a/ $\mathrm{W}$ is predicted, which is contradictory to the experimental results. However, eq (5) was derived for a constant constraint at the crack tip. Note that the term $(1-a / W)^{4} y^{2}$ also appears in eq (4). It seems the only way to explain the increase in transition temperature due to an increase in a/W ratio is through the constraint model. Specimens with larger a/W ratios produce higher plastic constraints, i.e., larger $\mathrm{L}$ values, and therefore compensate for the change in the $(1-a / w){ }^{4} y^{2}$ term. The steep slope of the transition curve for $a / W=0.75$ geometry has been attributed to the relaxation of the crack-tip constraint as the plastic zone approaches a free surface $[1,2]$.

The effect of thickness on the ductile-to-brittle transition temperature has been explained either by constraint effects $[1,2,4,5]$ or by statist1cal 
effects [23]. The former model attributes the decrease in transition temperature due to a reduction of specimen thickness to a loss in stress triaxiality at the crack tip, which reduces the effective flow stress in the plastic zone. On the basis of the statistical model, the effect of thickness is explained by the probability of the formation of crack nuclei within the volume of material sampled along the crack front. Therefore, the statistical model predicts a greater scatter in fracture toughness data for thin specimens than for thick specimens and a decrease in mean fracture toughness at a given temperature with increasing specimen thickness. The larger scatter in toughness data as a function of test temperature observed for the 12.7-mm-thick specimens (see figs. 25 and 26) may demonstrate the validity of the statistical model. However, with the limited data available, the effect of specimen thickness on the transition temperature cannot be strictly attributed to explanations of either of the above mentioned models. Most probably, both the constraint effects and statistical effects contribute to the shift in the transition temperature.

So far, the effects of thickness, material properties, and crack depth on the ductile-to-brittle transition temperature have been discussed. As far as design problems are concerned, specimen thickness seems to be the most important of these three variables; however, no well established theoretical treatment of its effect is known. Both constraint and statistical models predict a saturation thickness for a particular material, so that a further increase in specimen thickness will have no effect on measured fracture toughness. The results of this investigation indicate that at temperatures above $\mathrm{T}_{\mathrm{GY}}$ fracture is initiated by ductile fracture. This observation implies that the critical CTOD in the transition range is controlled by the subsequent propagation of a 
brittle crack from a ductile microcrack rather than the initial fatigue crack. Therefore, simplified theoretical treatments similar to what was given here, although qualitatively correct, may not be adequate for design purposes. It is suggested that the mechanisms that control the ductile-to-brittle transition curves are very complicated and a better understanding of stress and strain distributions and micromechanism of the fracture process ahead of a progressive blunting crack is required.

\section{Summary and Conclusions}

The ductile-to-brittle transition behavior of a shielded metal-arc weld, a typical steel weldment in arctic structures, has been studied and compared to that of the base metal, an ABS grade EH 36 steel in normalized condition. The toughness and the ductile-to-brittle transition temperature of the weld metal and the base metal measured by different test methods for various specimen geometries are summarized in table 6 . On the basis of the results obtained from tensile, Charpy V-notch, and fracture toughness testing and also scanning and optical microscopy, the following conclusions have been reached:

1. Specimen dimensions have a significant effect on the ductile-tobrittle transition curve. An increase in the specimen thickness from $12.7 \mathrm{~mm}$ to $25.4 \mathrm{~mm}$ for a/W $=0.2$ geometry resulted in an upward shift of $25^{\circ} \mathrm{C}$ in the ductile-to-brittle transition temperature. These results are consistent with the observations made for the base metal $[1,2]$.

2. In the transition region, crack initiation occurs by ductile fracture even for those specimens that do not show macroscopic slow crack 
growth. The ductile crack initiation was detected as a shear zone preceding the cleavage crack on the fracture surface.

3. The weld metal and the base metal have equal resistance to cleavage fracture, as indicated by equal $\mathrm{K}_{\mathrm{Ic}}$, tensile fracture stress, and CVN lower shelf energy values measured at low temperatures. However, the weld metal has a higher fracture toughness transition temperature, a result associated with the high strength and low resistance to ductile fracture of the weld metal.

4. The slope of the fracture toughness transition curve is the same in both the weld metal and the base metal. However, the weld metal has a much wider CVN transition temperature range than the base metal. The inconsistency between the results of CVN impact and fracture toughness testing in the ductile-to-brittle transition temperature range is suggested to be associated with the more complex fracture induced by CVN testing and the inhomogeneity of the weld metal microstructure.

5. There are two distinctly different microstructures in each weld pass. One consists of columnar prior austenite and acicular ferrite grain, and the other consists of equiaxed ferrite grains formed by reaustenitizing of the columnar microstructure. The results of this study suggest that the former microstructure has a lower fracture toughness and, when possible, the cleavage crack follows the blocky ferrite ( $\alpha$-veins) formed at the prior austenite grain boundaries. 


\section{References}

[1] T. L. Anderson and H. I. McHenry: "Fracture Toughness of Steel Weldments for Arctic Structures," NBSIR83-1680, National Bureau of Standards, Boulder, Colorado, 1982.

[2] T. L. Anderson: "The Effect of Crack-tip Region Constraint on Fracture in the Ductile-to-Brittle Transition Region", Ph.D. Thesis \#T-2741, Colorado School of Mines, Golden, Colorado, 1983.

[3] J. F. Knott: "Fundamentals of Fracture Mechanics", John Wiley and Sons, Inc., 1973.

[4] G. Green and J. F. Knott: J. Mech. Phys. Solids., 1975, vol. 23, p. 167.

[5] M. G. Dawes: in "Elastic-plastic Fracture", ASTM STP 668, J. D. Landes, J. A. Begley, and G. A. Clarke, Eds., American Society for Testing and Materials, 1979 , p. 307.

[6] I. Milne and G. G. Che11: in "Elastic-plastic Fracture", ASTM STP668

J. D. Landes, J. A. Begley, and G. A. Clarke, Eds., American Society for Testing and Materials, 1979, p. 358.

[7] G. E. Orowan: Rep. Prog. Phys., 1948, vol. 12, p. 185.

[8] S. T. Rolfe and J. M. Barsom: "Fracture and Fatigue Control in Structures", Prentice-Ha11, 1977, p. 92.

[9] B. Marander and G. Sanz: in ASTM STP 631, 1976, p. 72.

[10] I.-H. Lin, T. L. Anderson, R. deWit and M. G. Dawes: Int. J. Fracture, 1982, vol. 20, p. R3.

[11] Metals Handbook, "Welding and Brazing", eighth edition, vo1. 6, p. 191.

[12] D. McLean: "Mechanical Properties of Metals", John Wiley and Sons, 1962, p. 209.

[13] J. D. Harrison: "The State-of-the-Art in Crack Tip Opening Displacement (CTOD) Testing and Analysis", Report 非302.10/80/210.2, The Welding Institute, Abington, Cambridgeshire, England.

[14] J. R. Rice and M. A. Johnson: in "Inelastic Behavior of Solids", M. F. Kannien, et al., Eds., McGraw Hill, 1970, p. 641.

[15] T. R. Wilshaw, C. A. Rau, and A. S. Tetelman: Eng. Fract. Mech., 1968, vol. 1, p. 191.

[16] J. Malkin and A. S. Tetelman: Eng. Fract. Mech., 1971, vo1. 3, p. 151. 
[17] R. 0. Ritchie, J. F. Knott, and J. R. Rice: J. Mech. Phys. Solids, 1973, vol. 21, p. 395.

[18] J. F. Knott: Metal Sci., 1980, vol. 14, p. 327.

[19] F. Zia-Ebrahimi, D. K. Matlock, and G. Krauss: Scripta Meta11., 1982, vol. 16, p. 987.

[20] F. Zia-Ebrahimi and G. Krauss: Acta Metall., in press.

[21] F. Zia-Ebrahimi and G. Krauss: Met. Trans. A., 1983, vo1. 14, p. 1109.

[22] A. S. Tetelman and A. J. McEvily, Jr.: "Fracture of Structural Materials", John Wiley and Sons, 1967, p. 313.

[23] J. D. Landes and J. A. Begley: in ASTM STP 632, 1978, p. 57.

[24] R. 0. Ritchie, B. Francis and W. L. Server: Met. Trans. A., 1976, vol. 7, p. 831 . 
Type of process

Preheat

Electrode class and size

Welding position

Voltage, current (DCRP) and velocity
Manual shielded metal arc

None

$\mathrm{E} 80318,4.8,4.0$, and $3.2 \mathrm{~mm}$

Flat

$4.8 \mathrm{~mm}: 28 \mathrm{~V}, 210 \mathrm{~A}$

100-150 mm/min

$$
\begin{gathered}
4.0 \mathrm{~mm}: 25 \mathrm{~V}, 170 \mathrm{~A} \\
100-125 \mathrm{~mm} / \mathrm{min}
\end{gathered}
$$

$3.2 \mathrm{~mm}: 23 \mathrm{~V}, 120 \mathrm{~A}$ $75 \mathrm{~mm} / \mathrm{min}$

Joint design and

bead placement

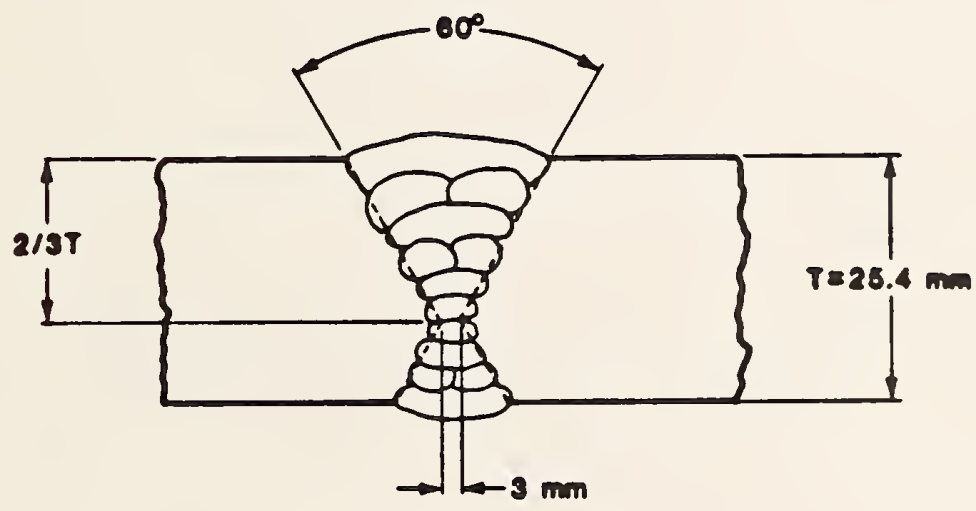


Table 2. Test matrix for fracture toughness tests of welded SENB specimens
$a / w$
$B=12.7 \mathrm{~mm}$
$B=25.4 \mathrm{~mm}$

0.25

$\mathrm{X}$

$\mathrm{X}$

0.5

$\mathrm{X}$

0.75

$\mathrm{X}$

$\mathrm{W}=21.8 \mathrm{~mm}$ 


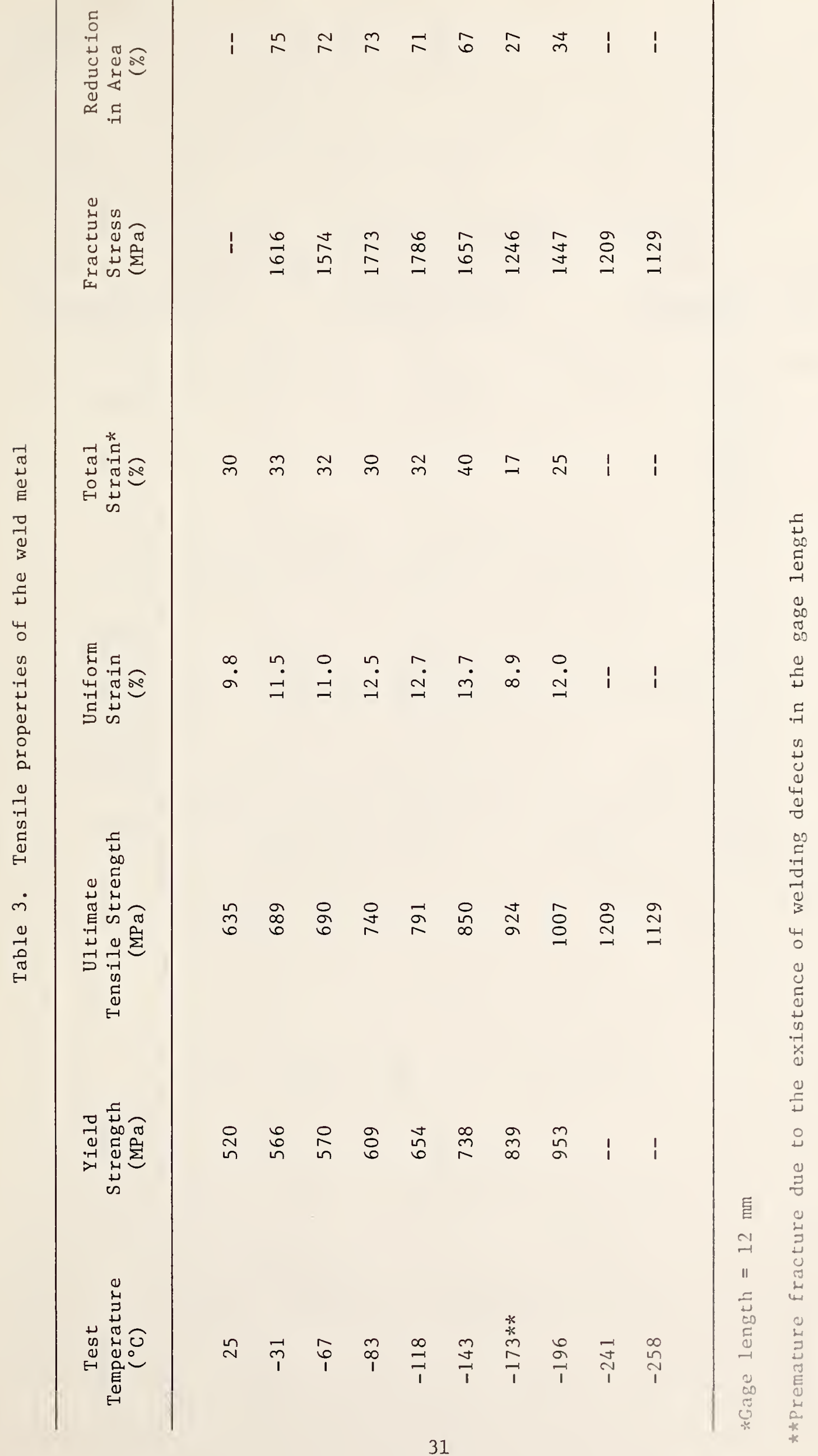


Table 4. Charpy V-notch data for the weld metal

\begin{tabular}{ccc}
\hline $\begin{array}{c}\text { Test } \begin{array}{c}\text { Temperature } \\
\left.{ }^{\circ} \mathrm{C}\right)\end{array} \\
(\mathrm{J})\end{array}$ & $\begin{array}{c}\text { Absorbed Energy } \\
(\mathrm{mm})\end{array}$ \\
\hline 58 & 203 & 2.137 \\
25 & 182 & 2.180 \\
1 & 161 & 1.948 \\
-6 & 126 & 1.644 \\
-24 & 122 & 1.619 \\
-35 & 80 & 1.145 \\
-45 & 89 & 1.218 \\
-73 & 80 & 1.123 \\
-94 & 27 & 0.424 \\
\hline
\end{tabular}




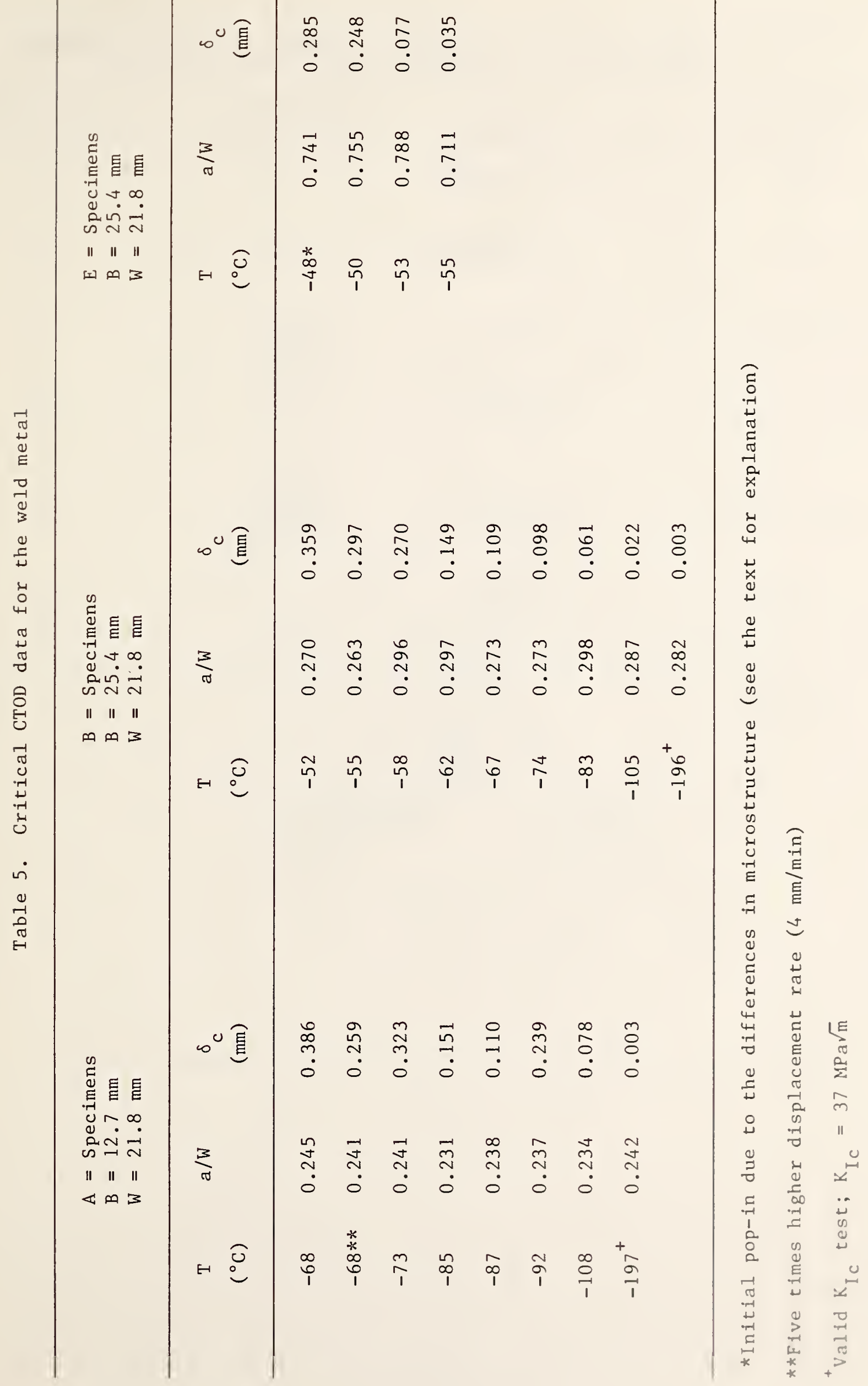


Table 6. Summary of the toughness and the ductile-to-brittle transition temperature data for the base metal and the weld metal

\begin{tabular}{llcc}
\hline Conditions & Parameter & Base Metal & Weld Metal \\
\hline $\mathrm{T}=-196{ }^{\circ} \mathrm{C}$ & $\mathrm{K}_{\mathrm{IC}}(\mathrm{MPa} \sqrt{\mathrm{m}})$ & 37 & 37 \\
$\mathrm{~T}=60^{\circ} \mathrm{C}$ & $\mathrm{CVN}$ Energy $(\mathrm{J})$ & 335 & 47.8 \\
$\mathrm{CVN}$ Energy $=27 \mathrm{~J}$ & $\mathrm{~T}\left({ }^{\circ} \mathrm{C}\right)$ & -78 & -74 \\
$\mathrm{~B}=12.7 \mathrm{~mm}$ & $\mathrm{~T}$ & & -98 \\
$\mathrm{a} / \mathrm{W}=0.2-0.25$ & $\mathrm{~T}_{\mathrm{GY}}\left({ }^{\circ} \mathrm{C}\right)$ & -140 & -79 \\
$\mathrm{~T}\left({ }^{\circ} \mathrm{C}\right)$ & -128 & -83 \\
$\mathrm{~B} / \mathrm{W}=0.75$ & $\mathrm{~T}_{\mathrm{GY}}\left({ }^{\circ} \mathrm{C}\right)$ & & -59 \\
$\mathrm{~B}=25.4 \mathrm{~mm}$ & $\mathrm{~T}\left({ }^{\circ} \mathrm{C}\right)$ & -130 & \\
$\mathrm{a} / \mathrm{W}=0.2-0.25$ & $\mathrm{~T}$ & -111 & -55 \\
\hline $\mathrm{Gm}$ & $\mathrm{T}\left({ }^{\circ} \mathrm{C}\right) *$ & -120 & -50 \\
\hline
\end{tabular}

${ }^{*} \delta_{c}=0.2 \mathrm{~mm}$ 


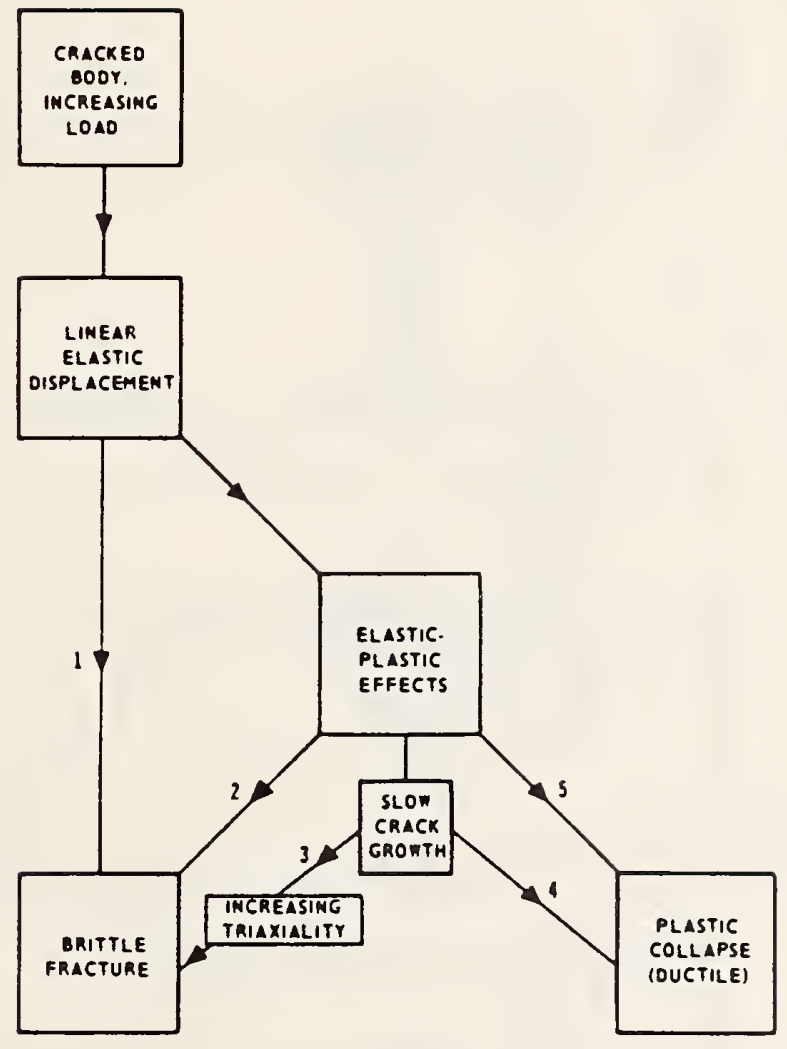

Figure 1. The various failure path that a cracked body can follow. 


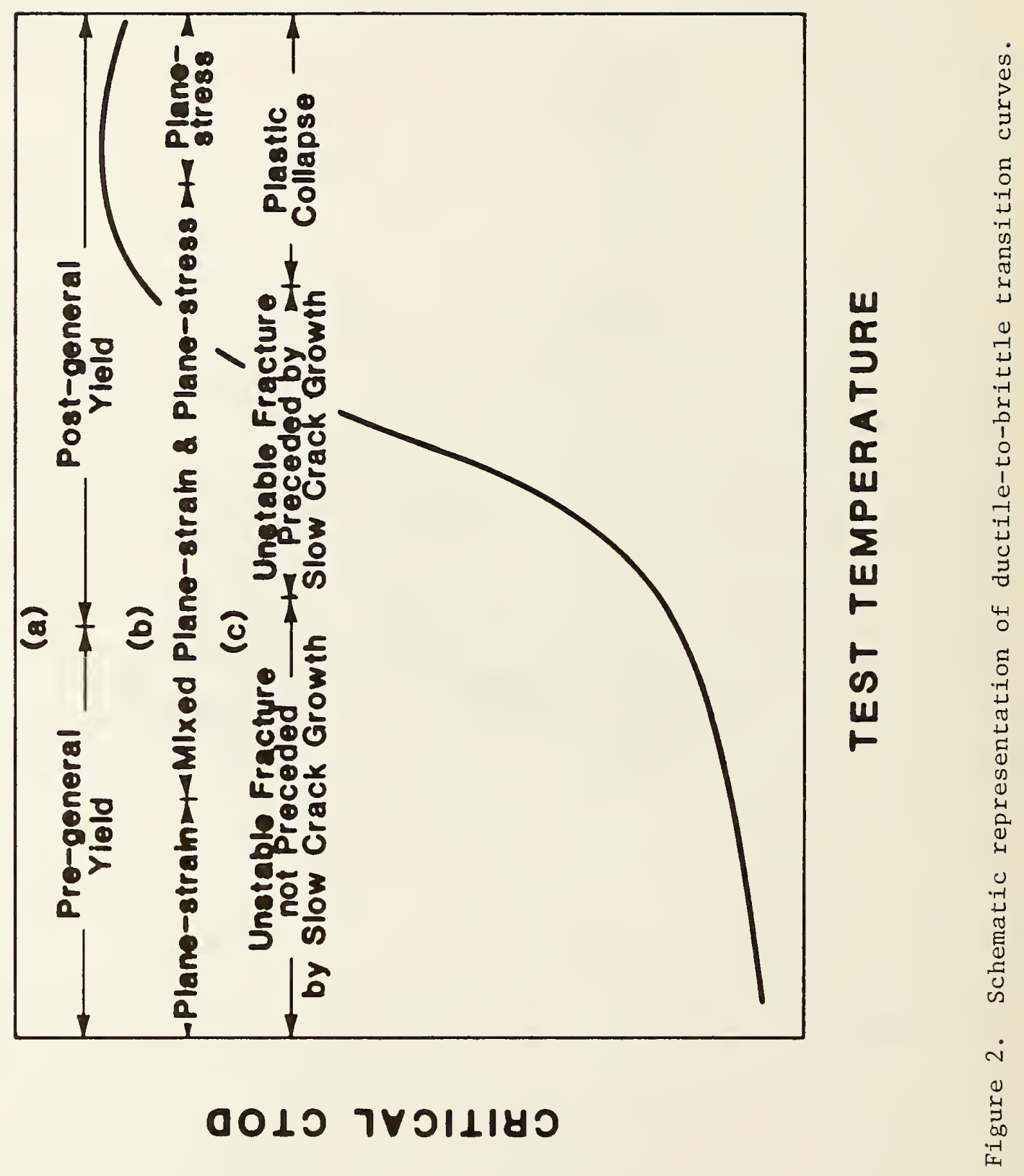




\section{Rolling Direction $\rightarrow$}

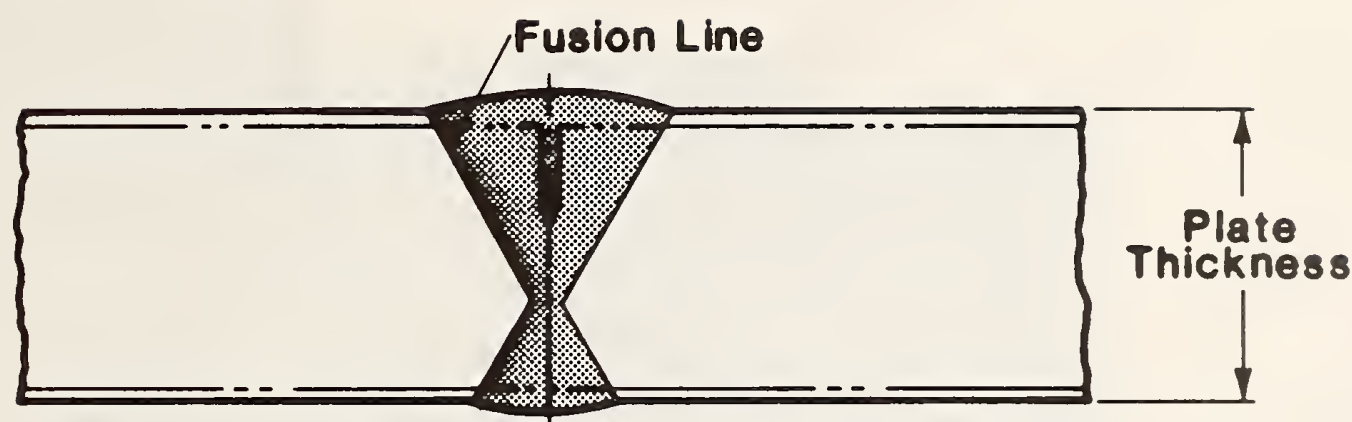

a) SENB Specimen

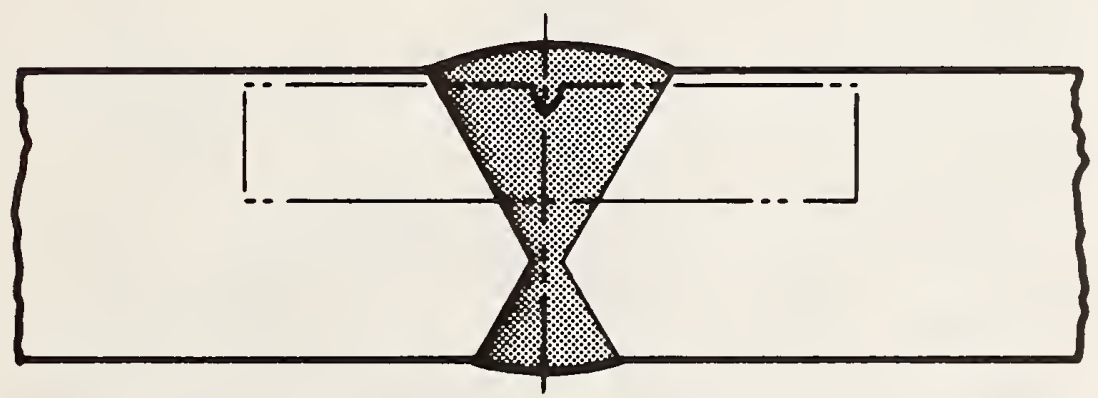

b) CVN Specimen

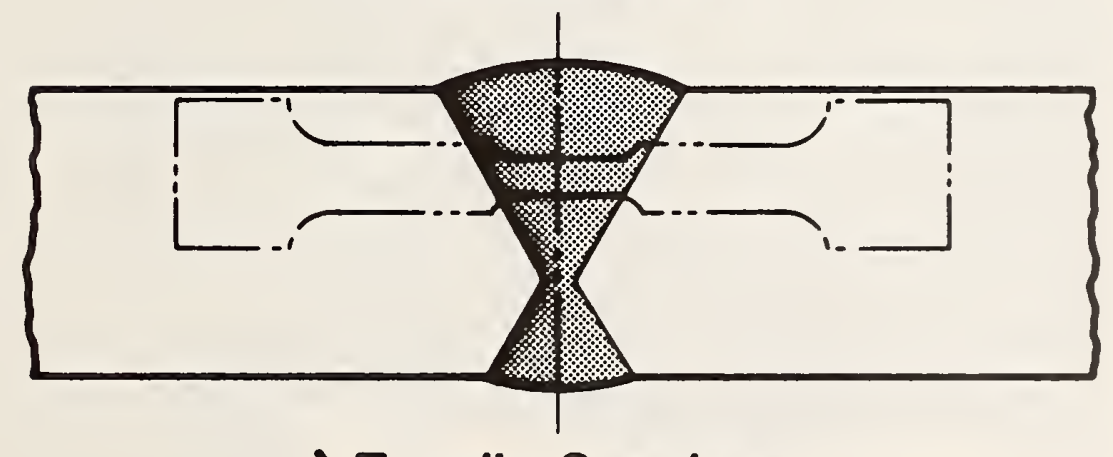

c) Tensile Specimen

Figure 3. The orientation of the test specimens relative to the steel weldment. 

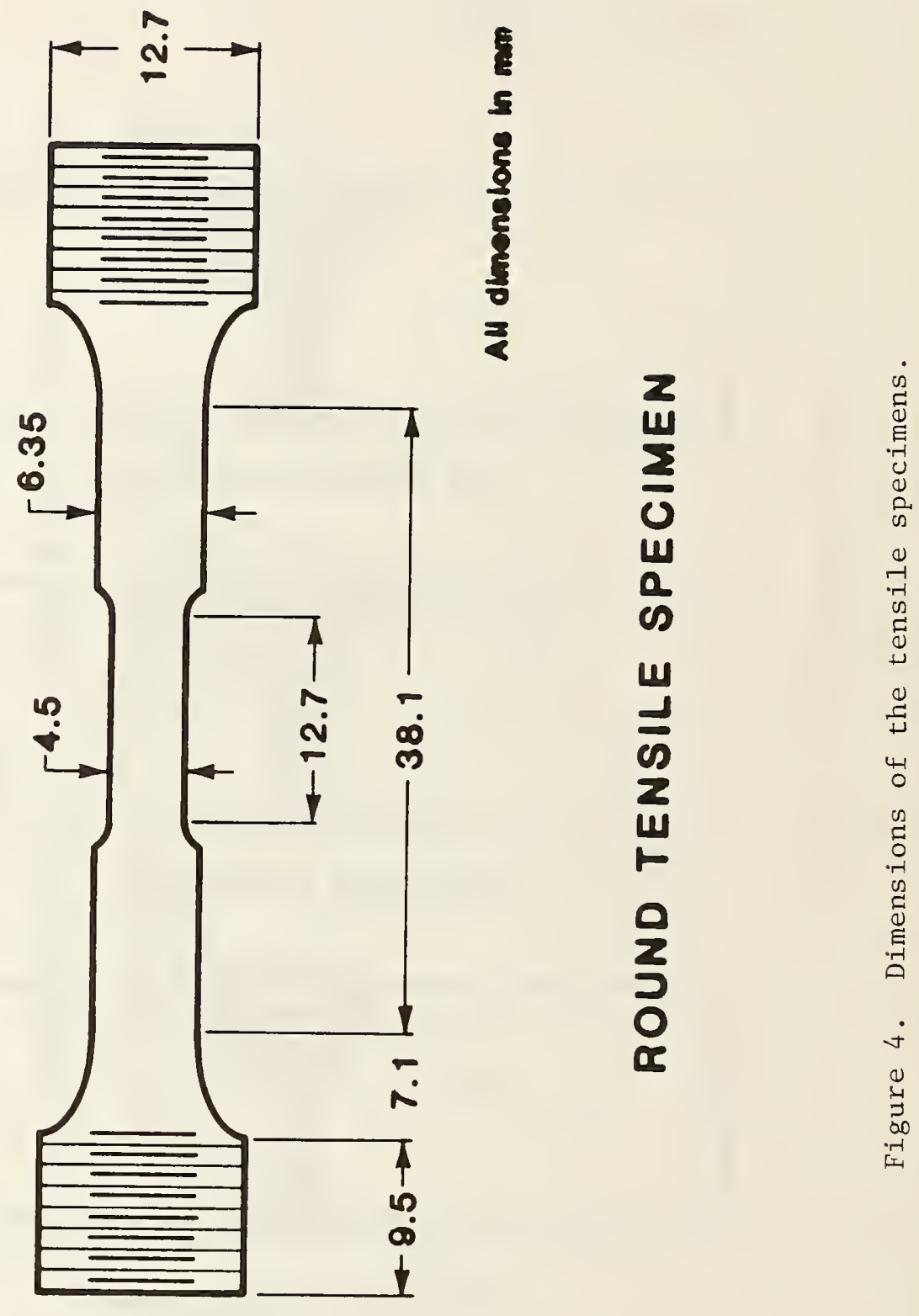


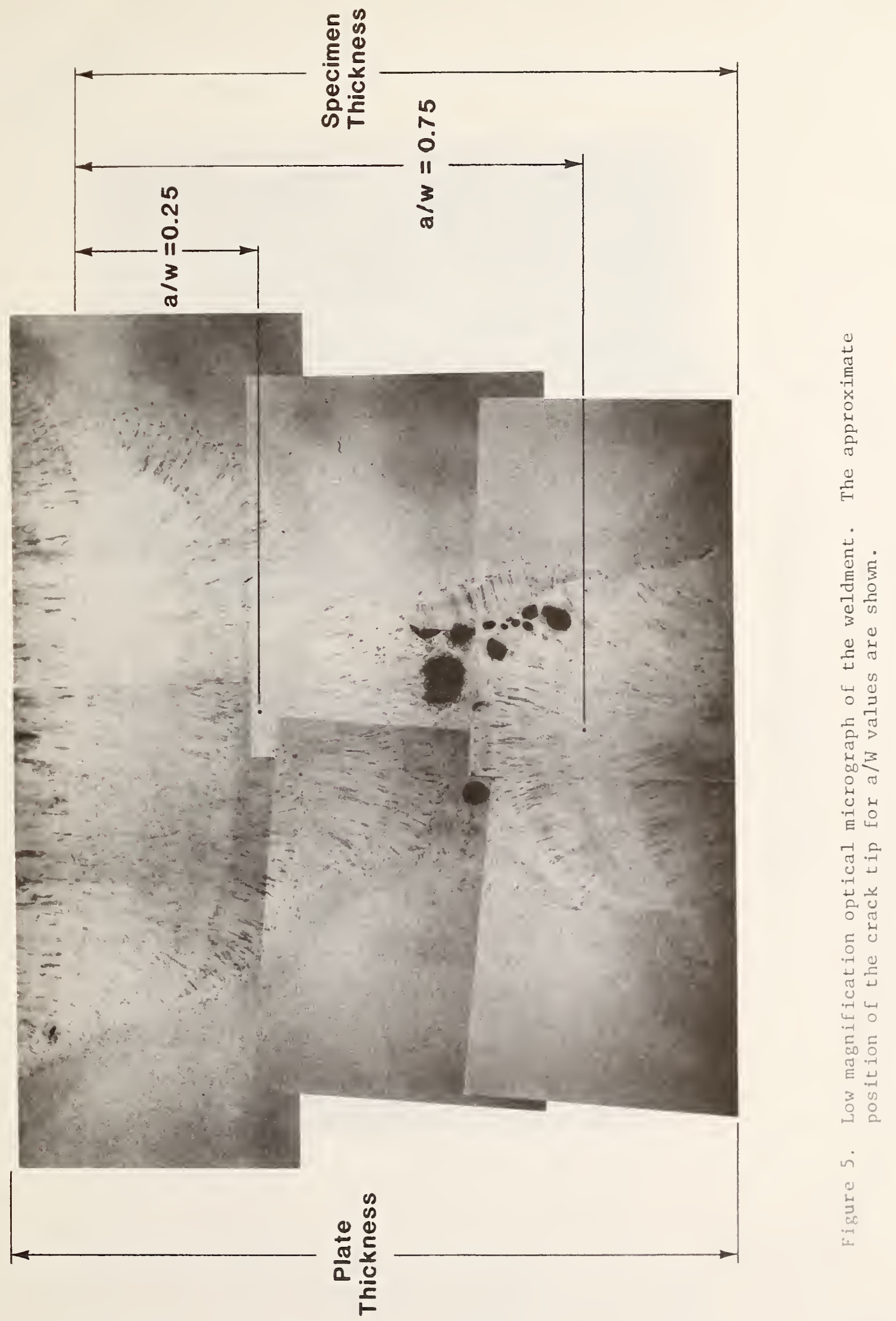



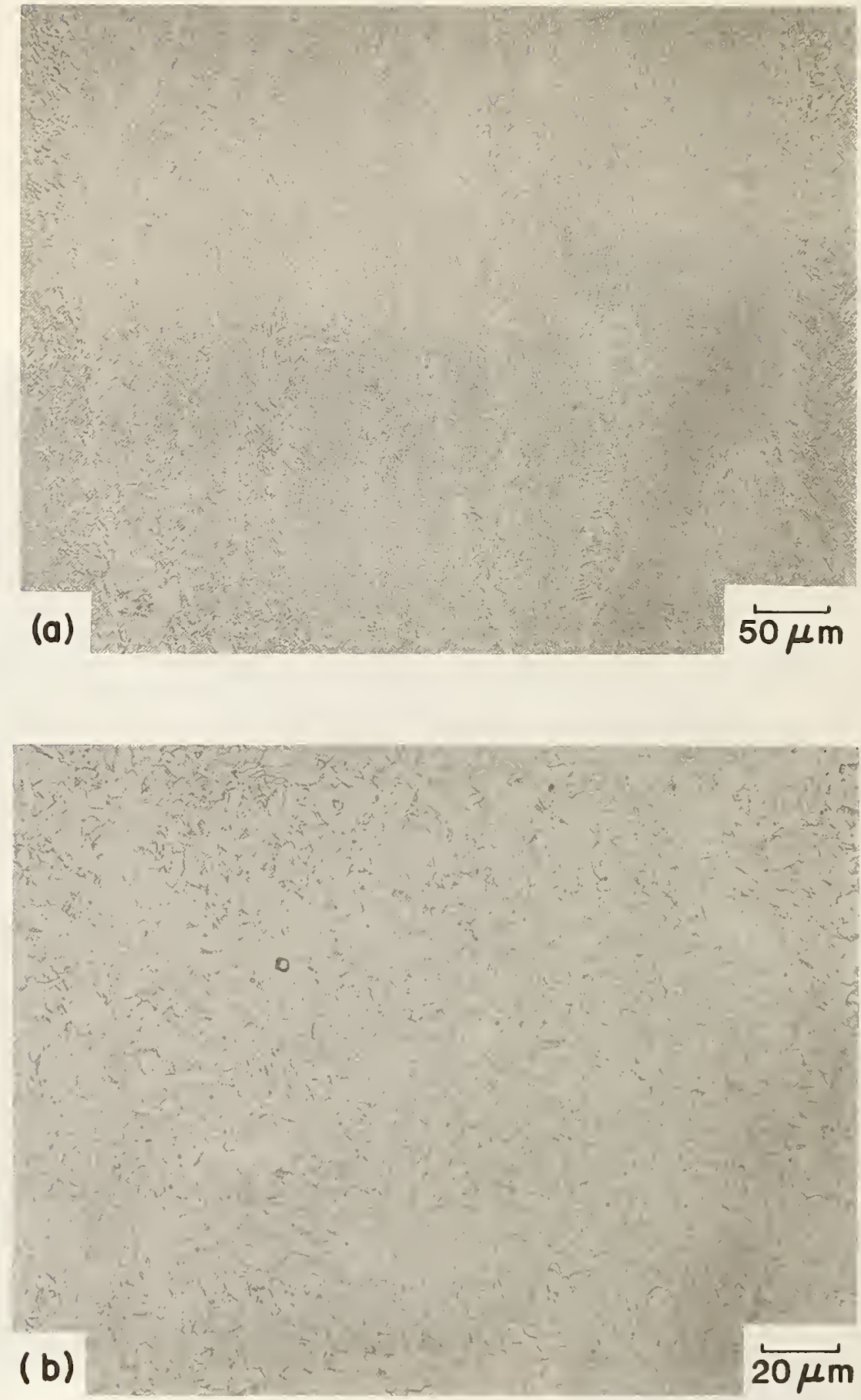

Figure 6. Two distinctively different microstructures of the weld metal. (a) Columnar prior austentite grains, blocky ferrite at the grain boundaries and acicular ferrite. (b) Fine equixed ferrite grains. 


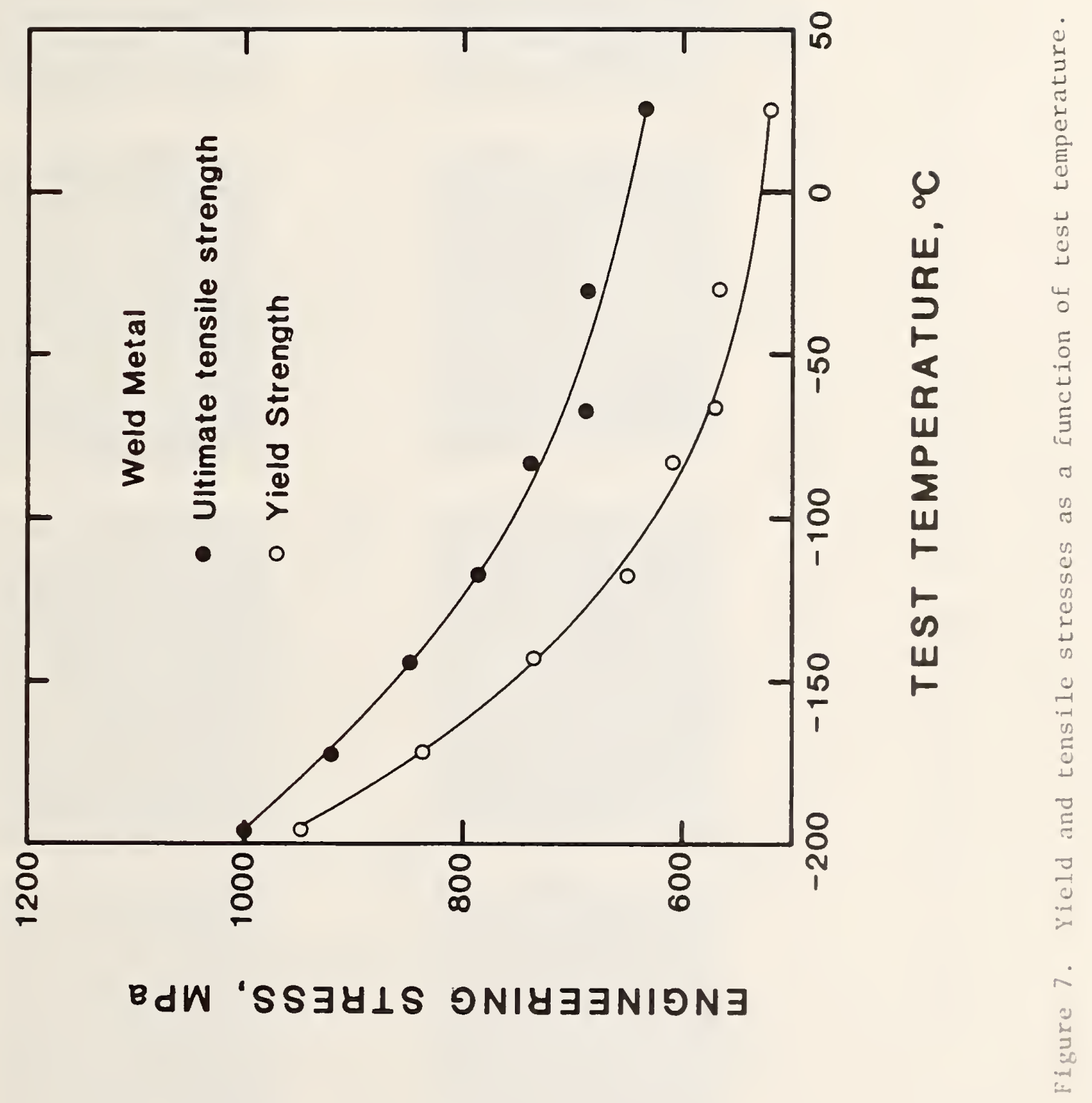




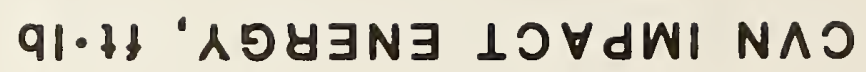

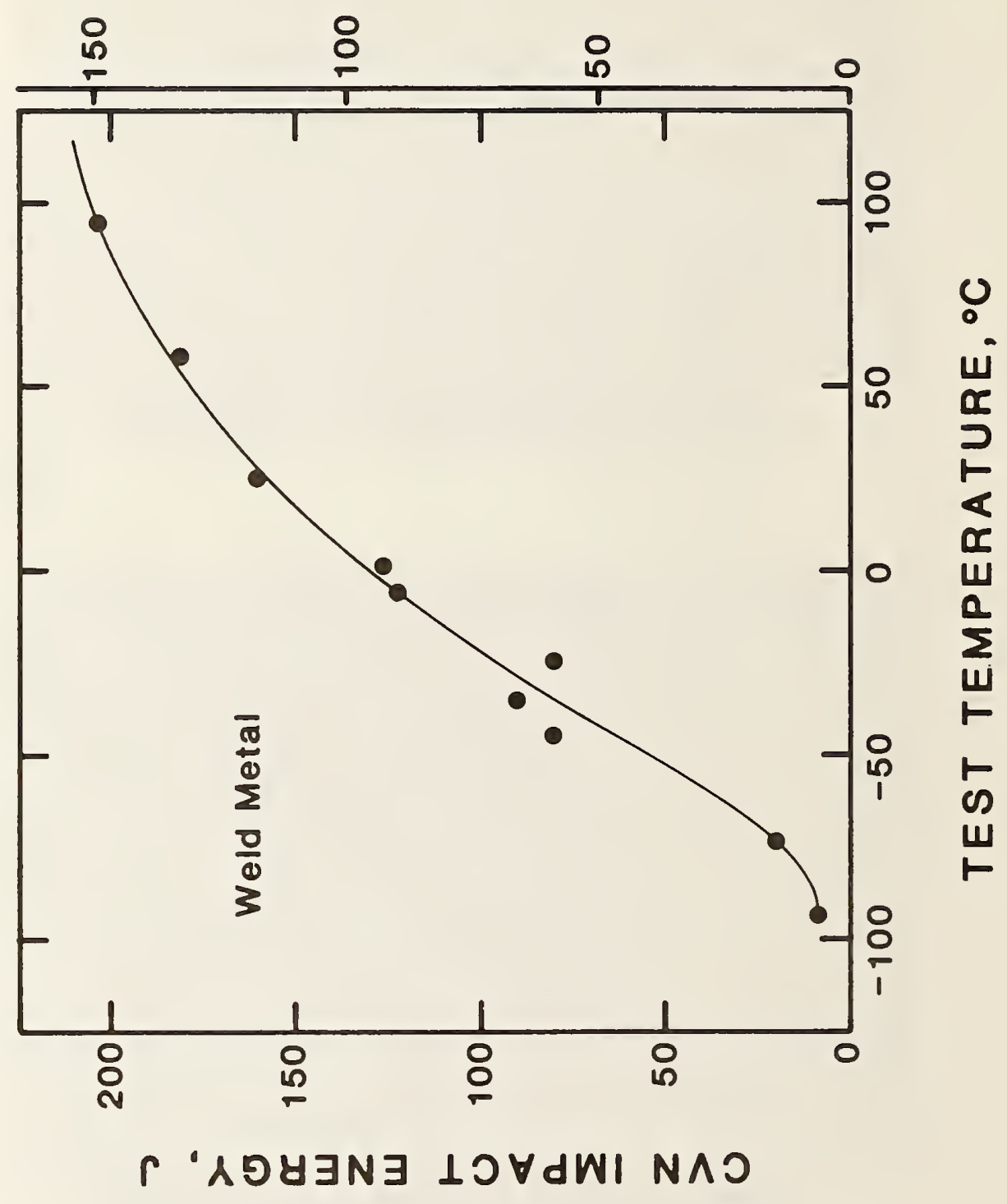

D 

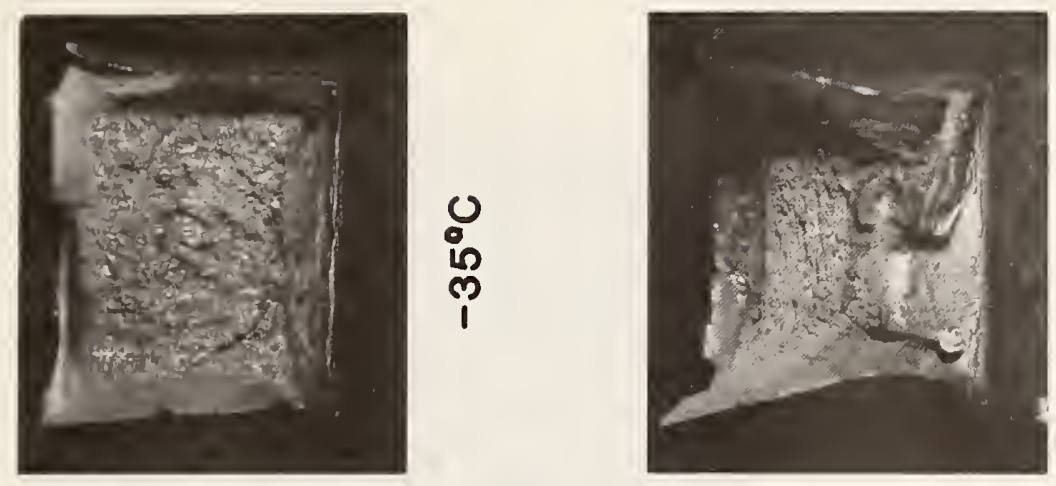

0
o.
के
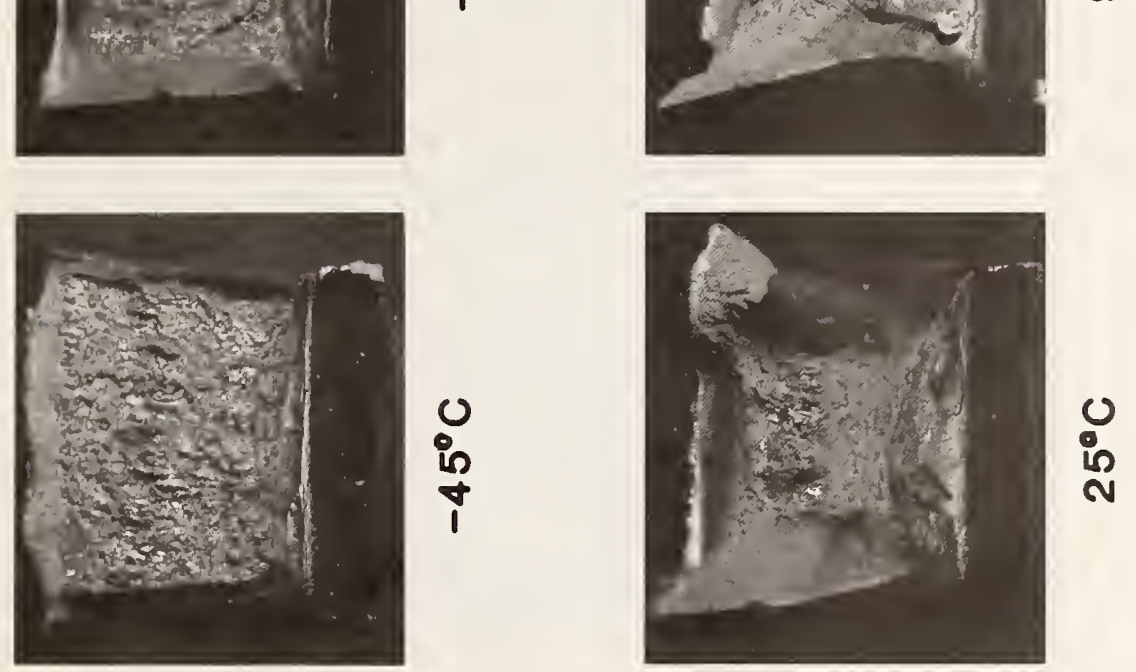

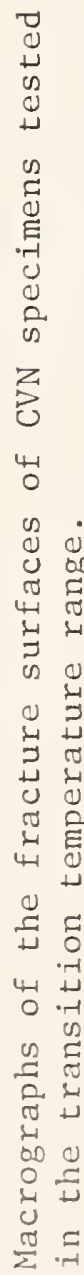
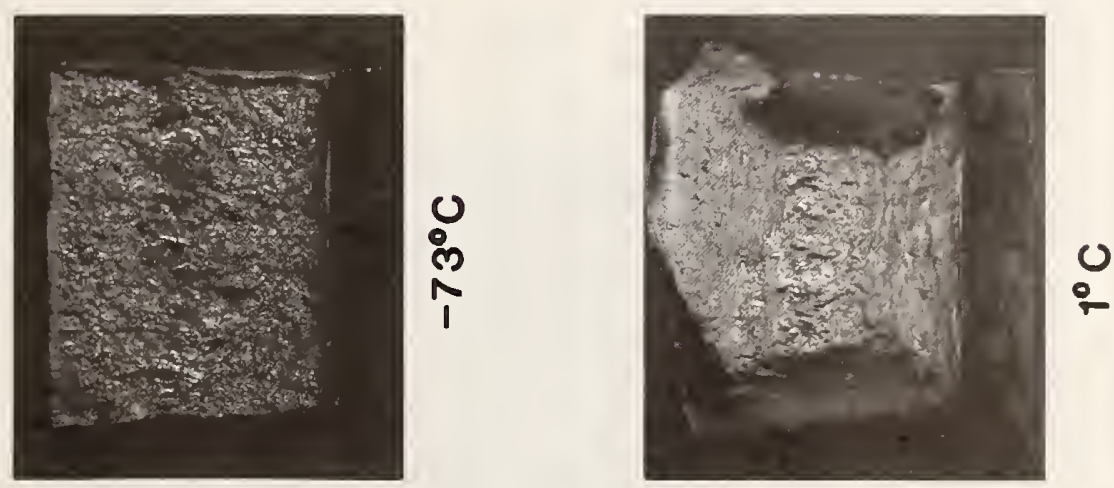

0
in
N

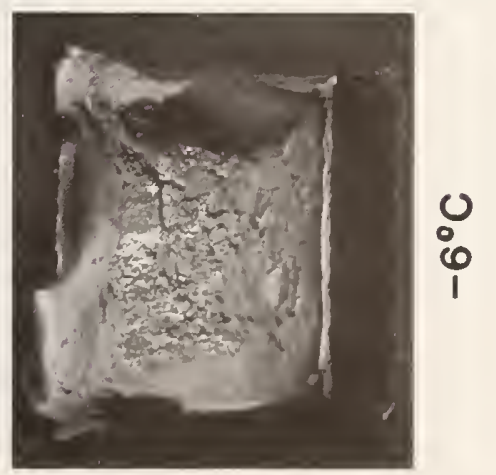

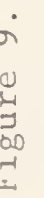

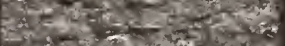
$15 x+3 \times 2$ kes 50 in 5

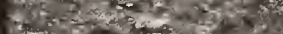

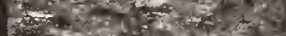
t

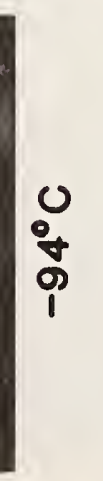

i 

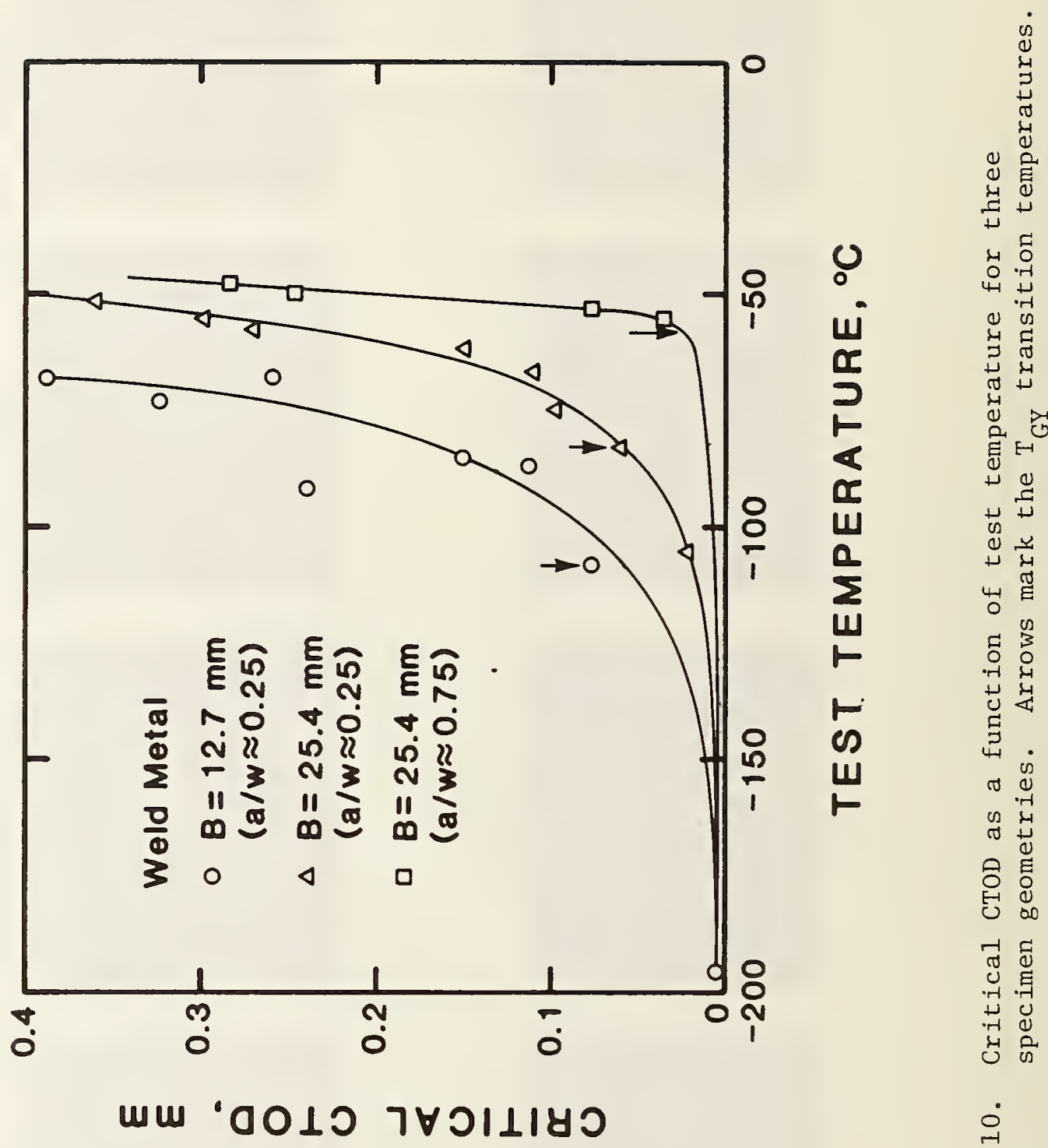

0
01
0
4
$y$
00
$i-1$
$x y$ 

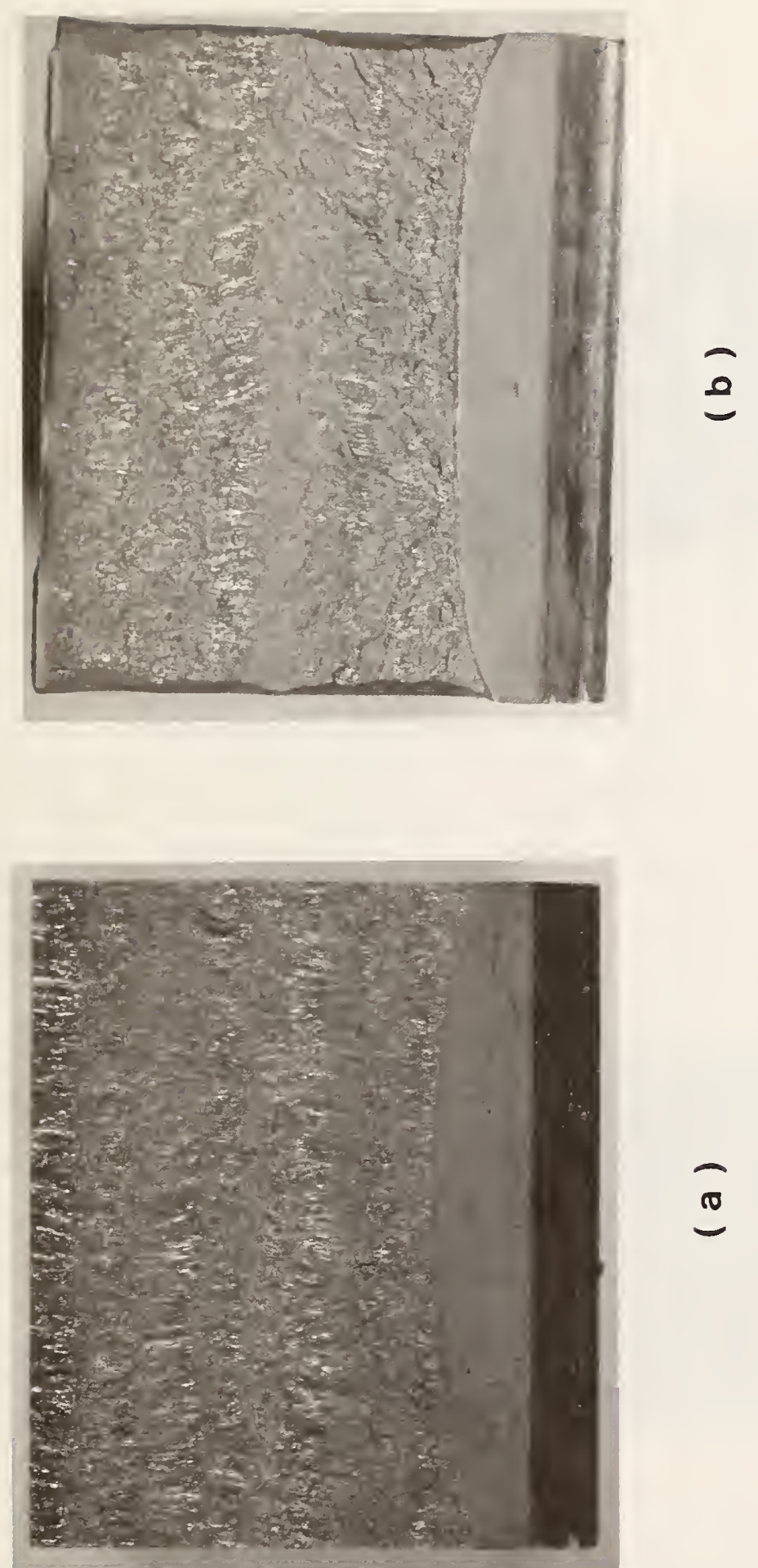

章

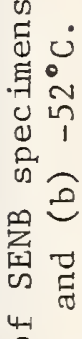

40

0 0

บै สิ

.

के

0

$\exists$ ज

$\Delta$

$\pi$

प्र क क

ب

工

넝

ह5

tr

o.

는

幽

I

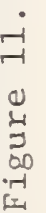



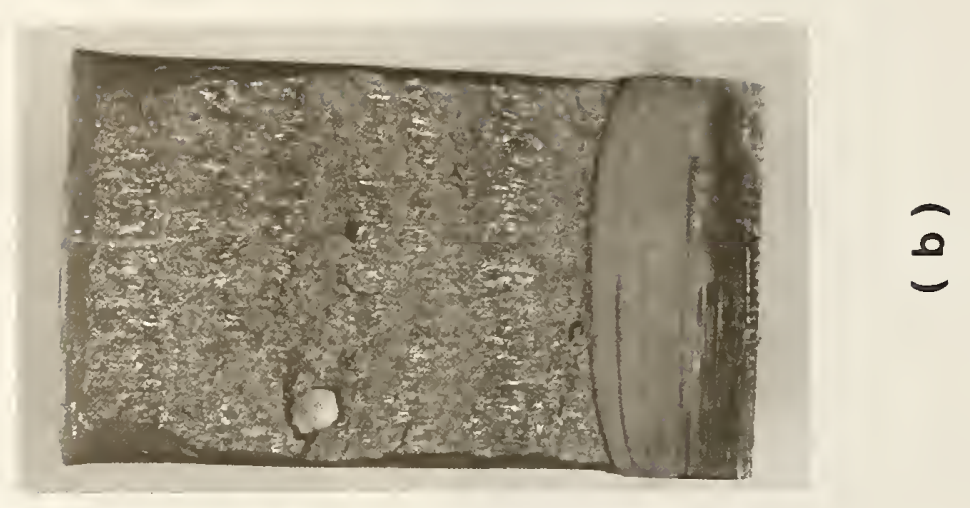

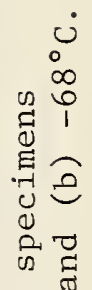

艺。

되 으

出

ช

$\pi$

는

के

(1)

넉

0

菏

4 过

()

I $\infty$

出目

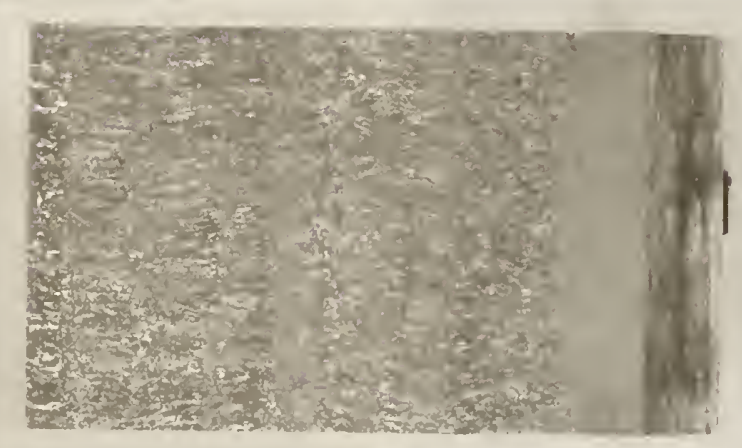

क

हैं

저

$\infty \infty$

옹

盛

I

2
-1
0
0
0
0.0
-1
$i=1$ 


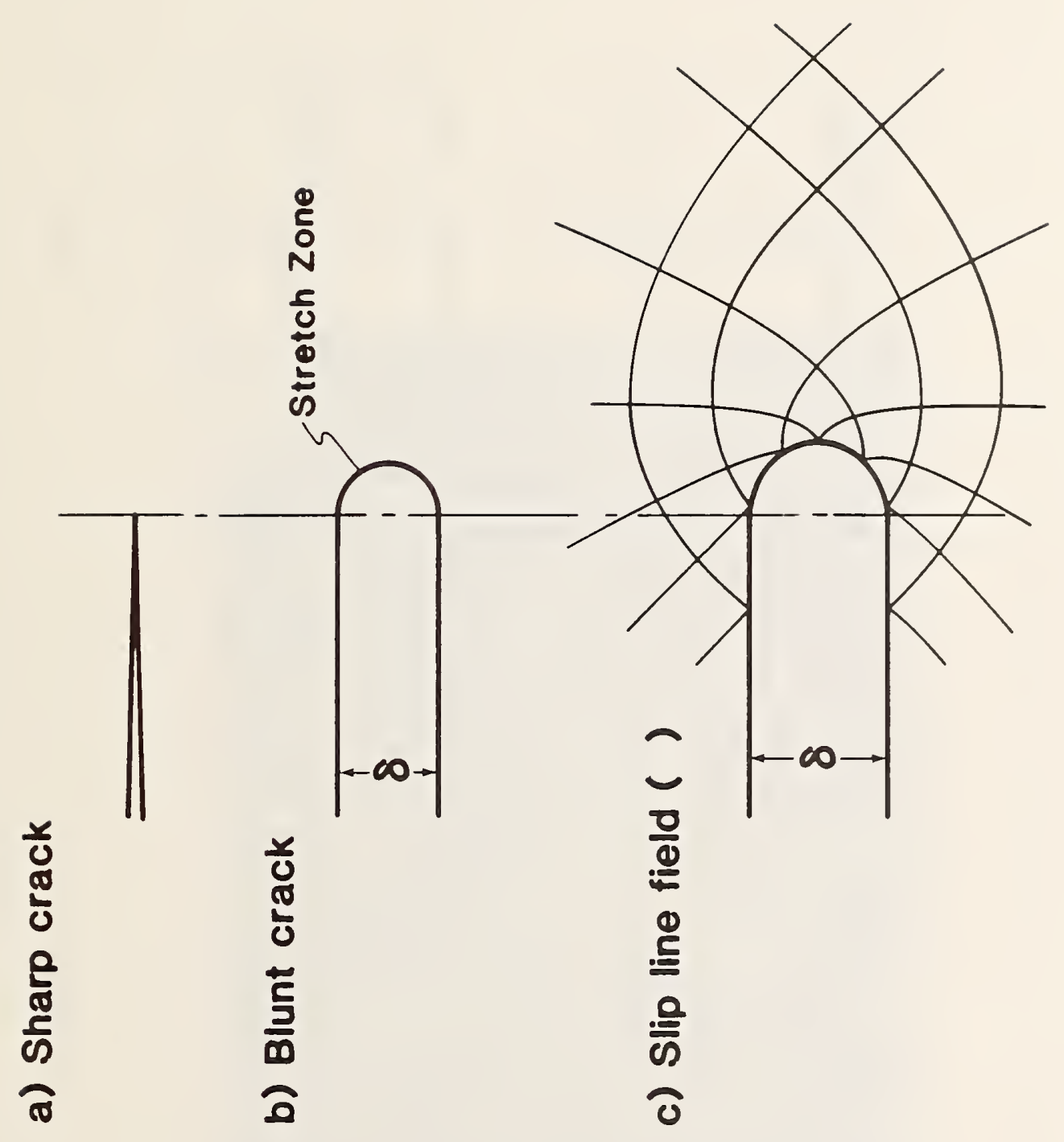

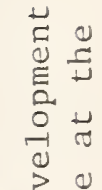
Е

- उิ

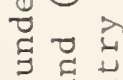
चै है t) 0 บ $\stackrel{0}{N} 0$ वै क्ष $\Xi \pm-$ כ出至 อ운 艺㟧寻 毛 50 (도․

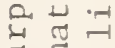
施 तु

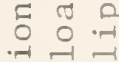
菏 is.

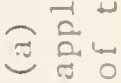
$m$
$m$
0
0 


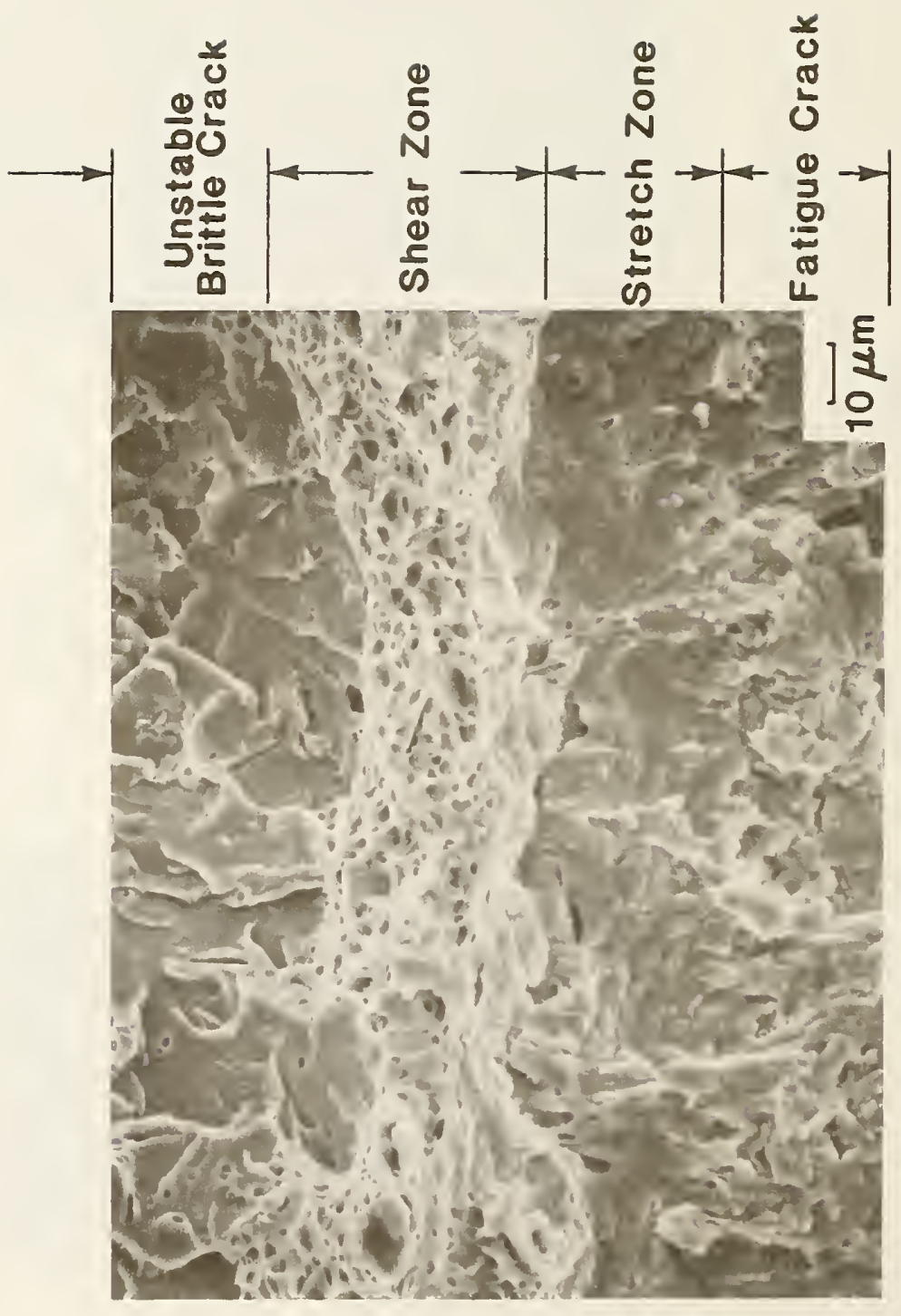

岂 ๘ 茴 0 4 प्र० บ 0 (1) 1 के 건 मा त तु 䏓

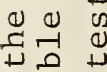
$00+2$ E्ञ त्र 350 क 吾 氙署 प a 웝 U $\mathrm{O}$ N - $\infty$ फ

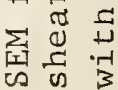

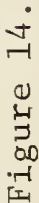



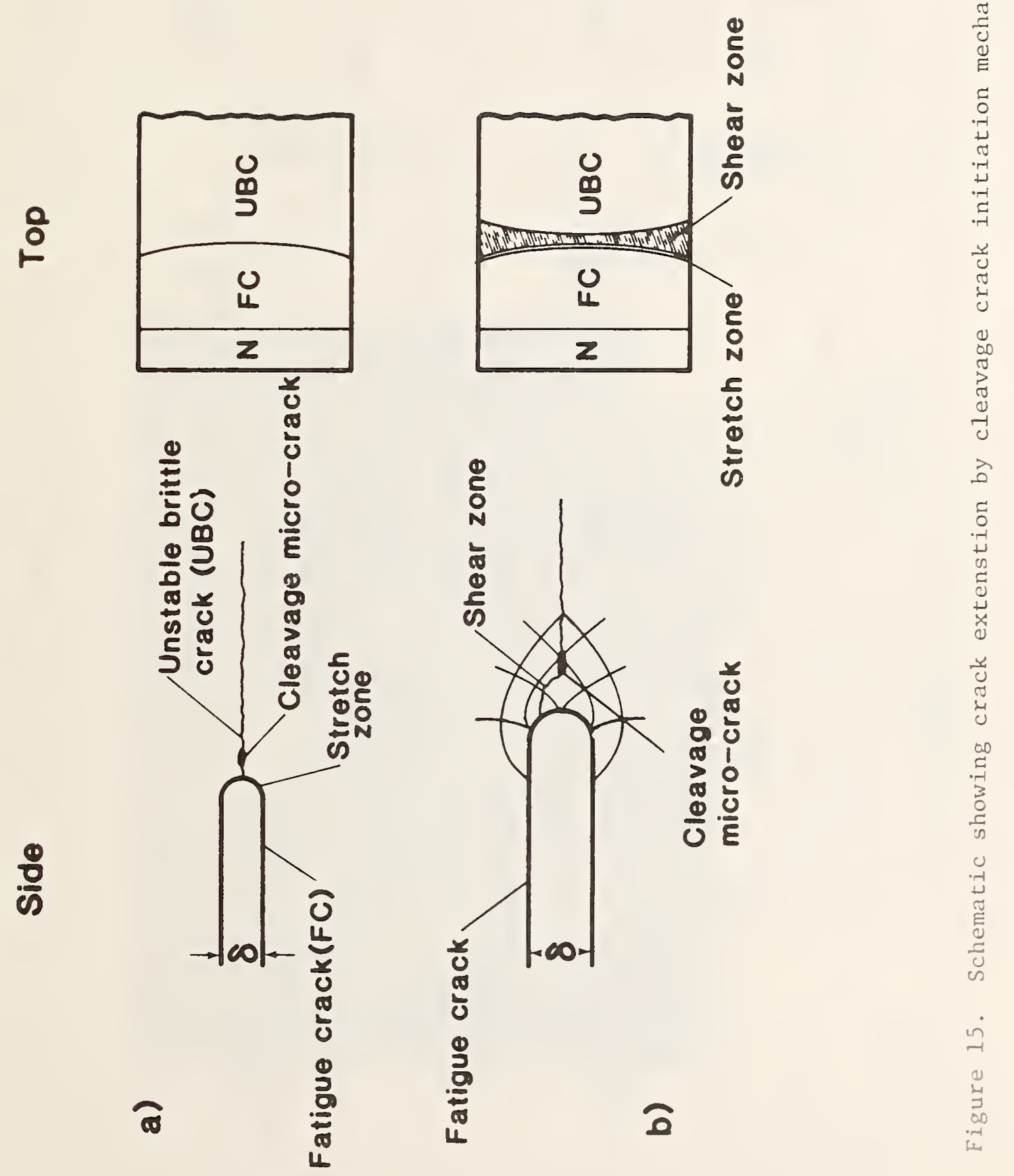
웅

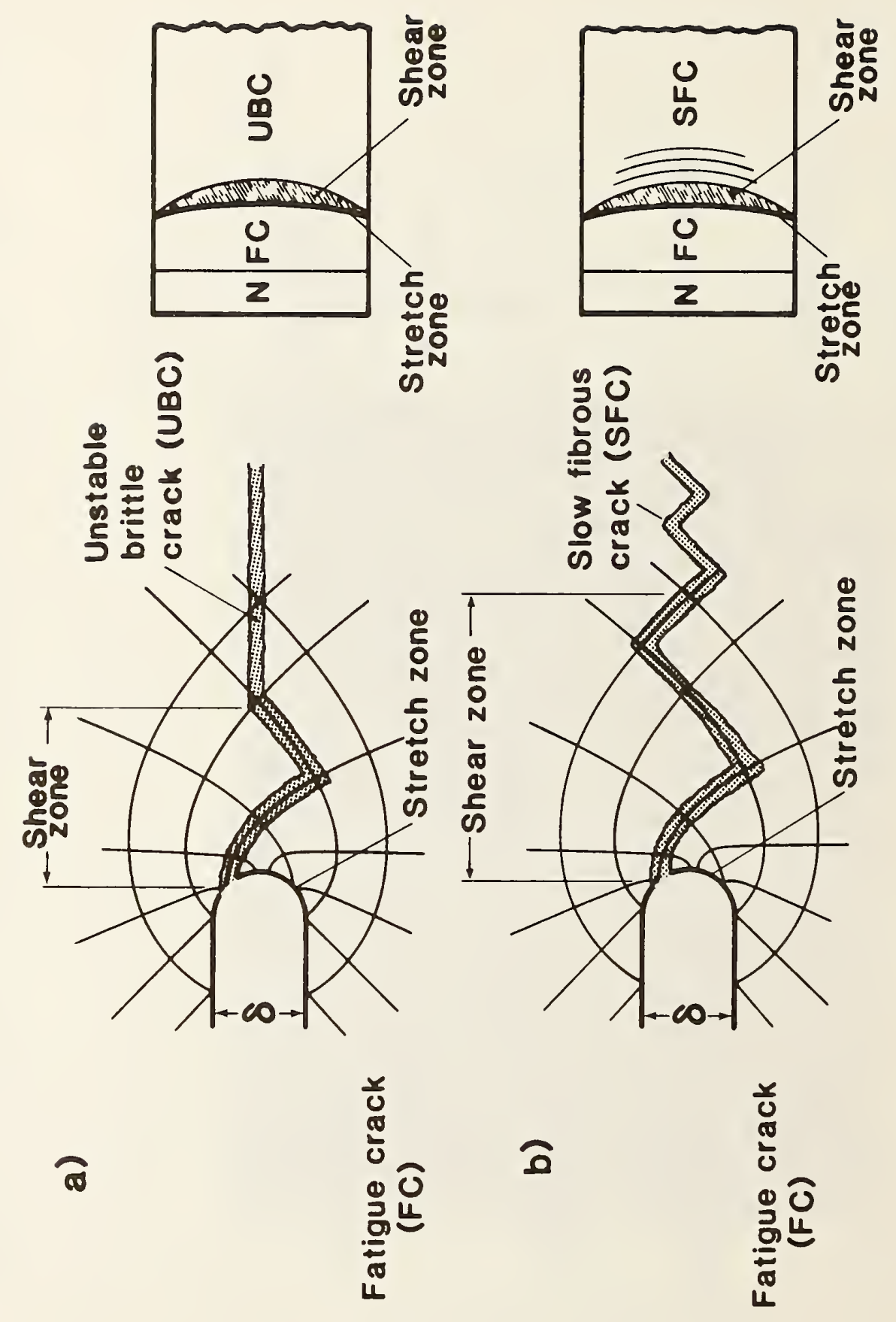

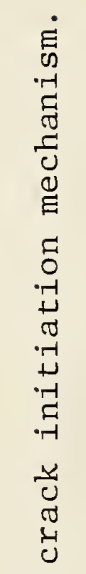

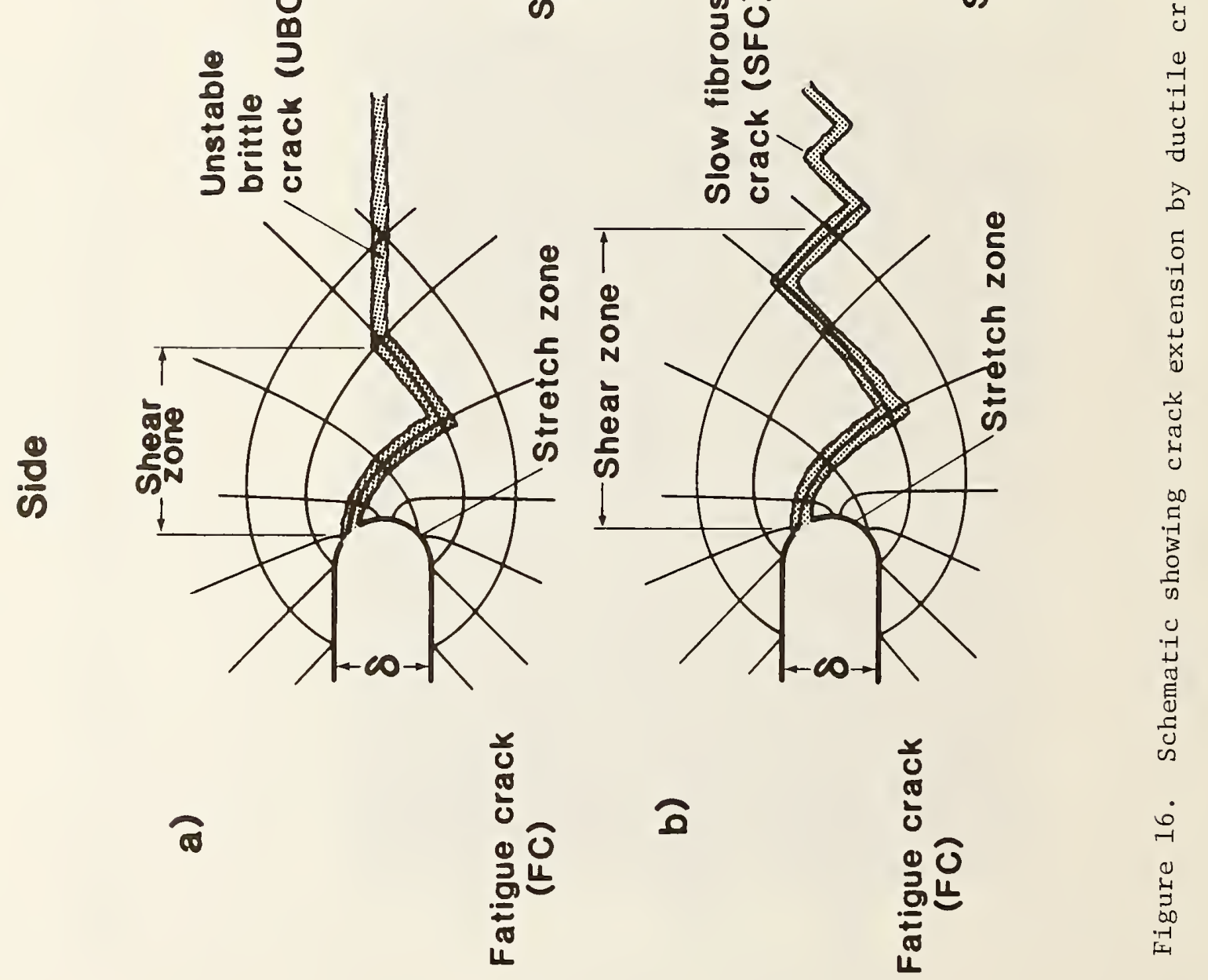




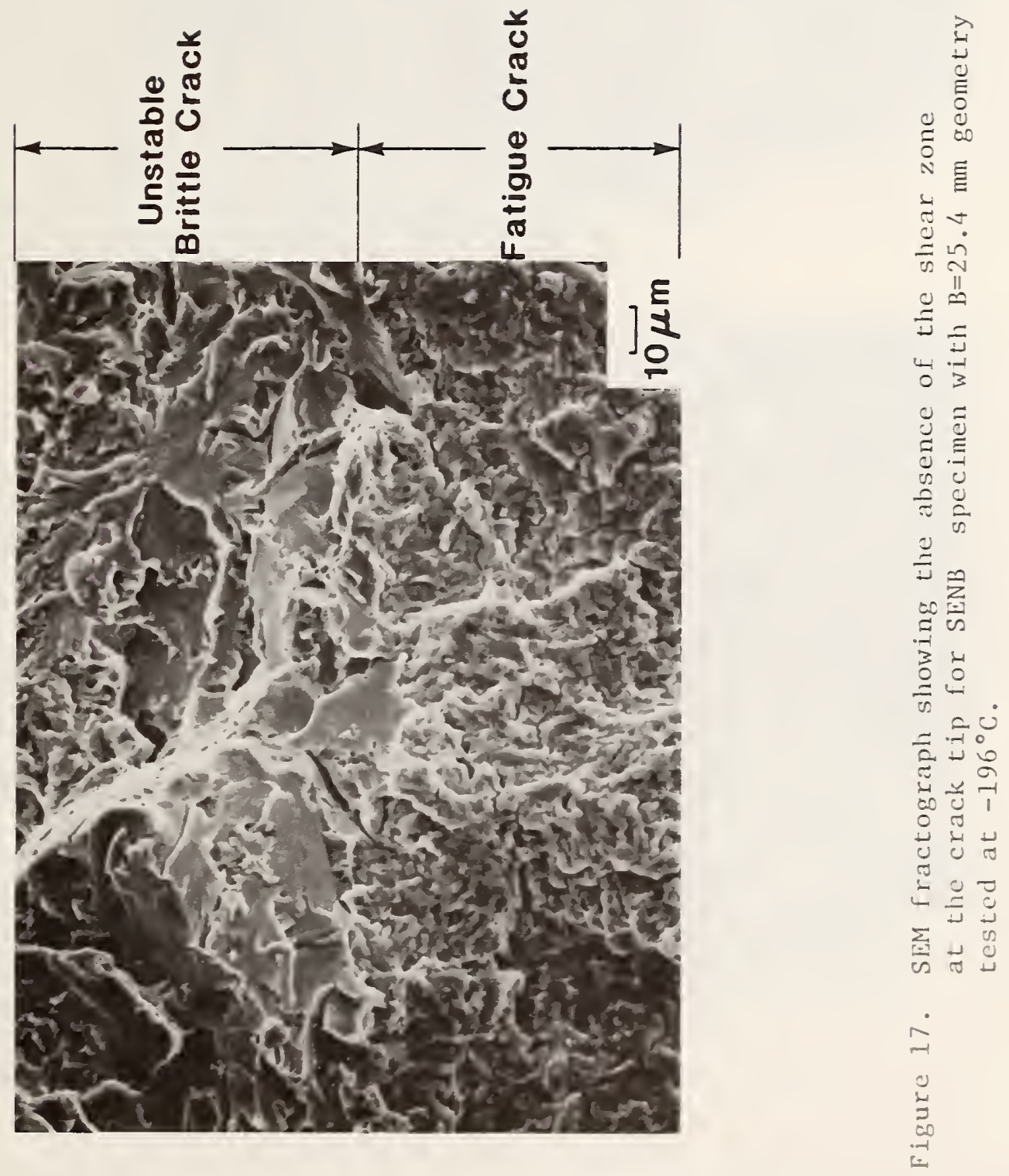



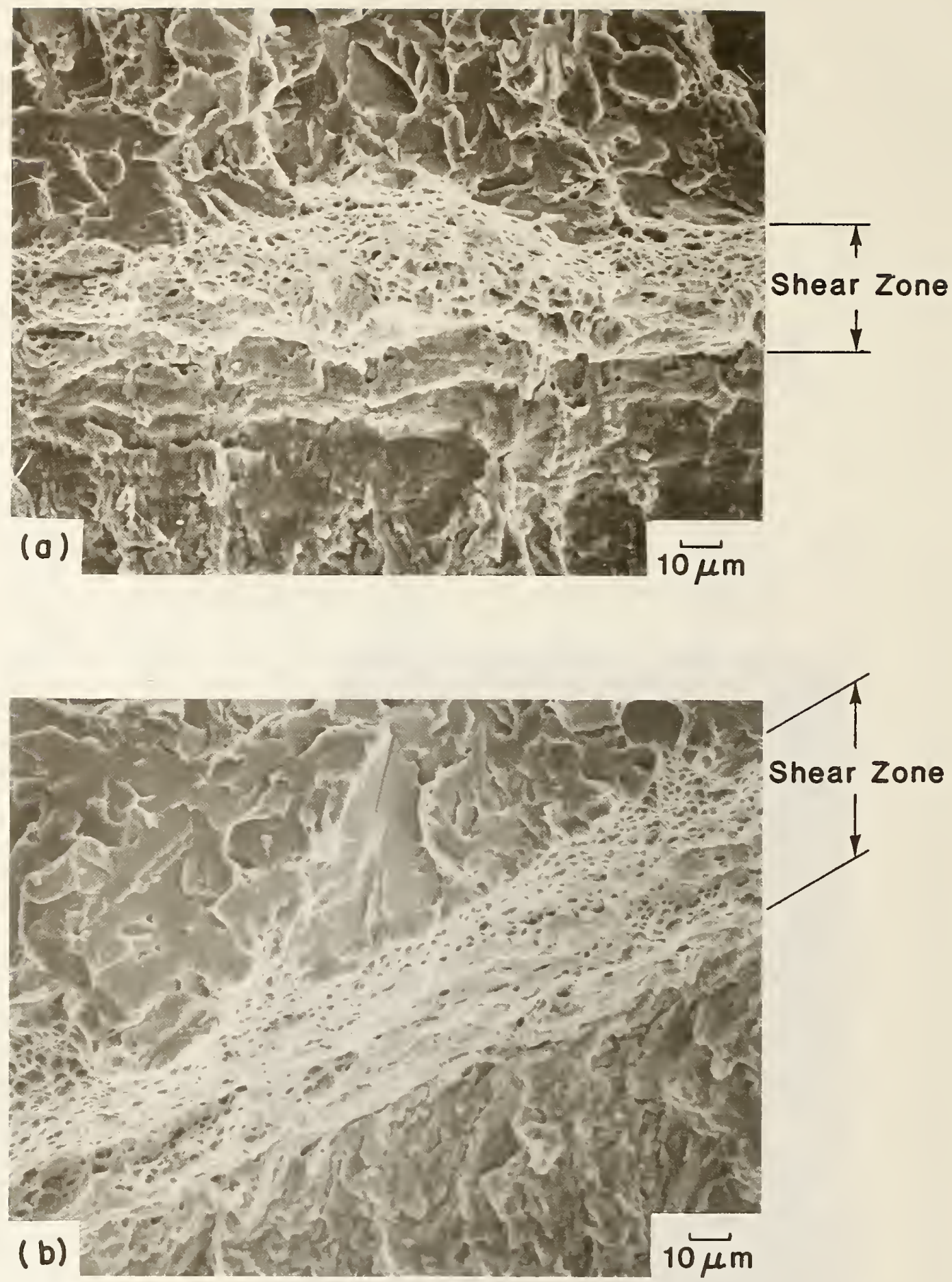

Figure 18. SEM fractographs showing the difference in the size of the sheat zone formed at (a) the midthickness and (b) the edge of the specimen. SENB specimen with $B=2.5 .4 \mathrm{~mm}$ geometry tested at $-74^{\circ} \mathrm{C}$. 

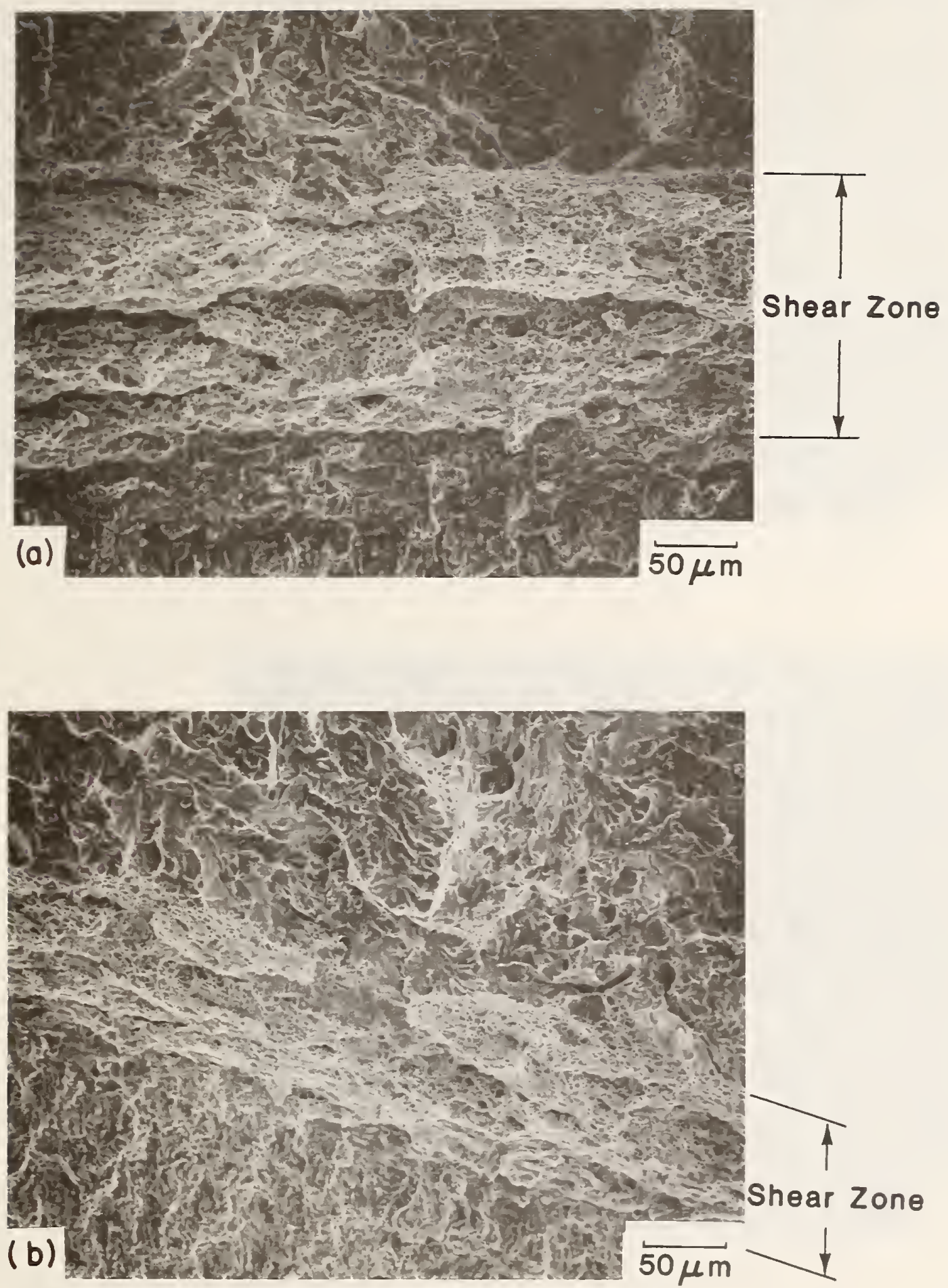

Figure 19. SEM fractographs showing the difference in the size of the shear zone formed at (a) the midthickness and (b) the edge of the specimen. SENB specimen with $B=12.7 \mathrm{~mm}$ geometry tested at $-68^{\circ} \mathrm{C}$. 

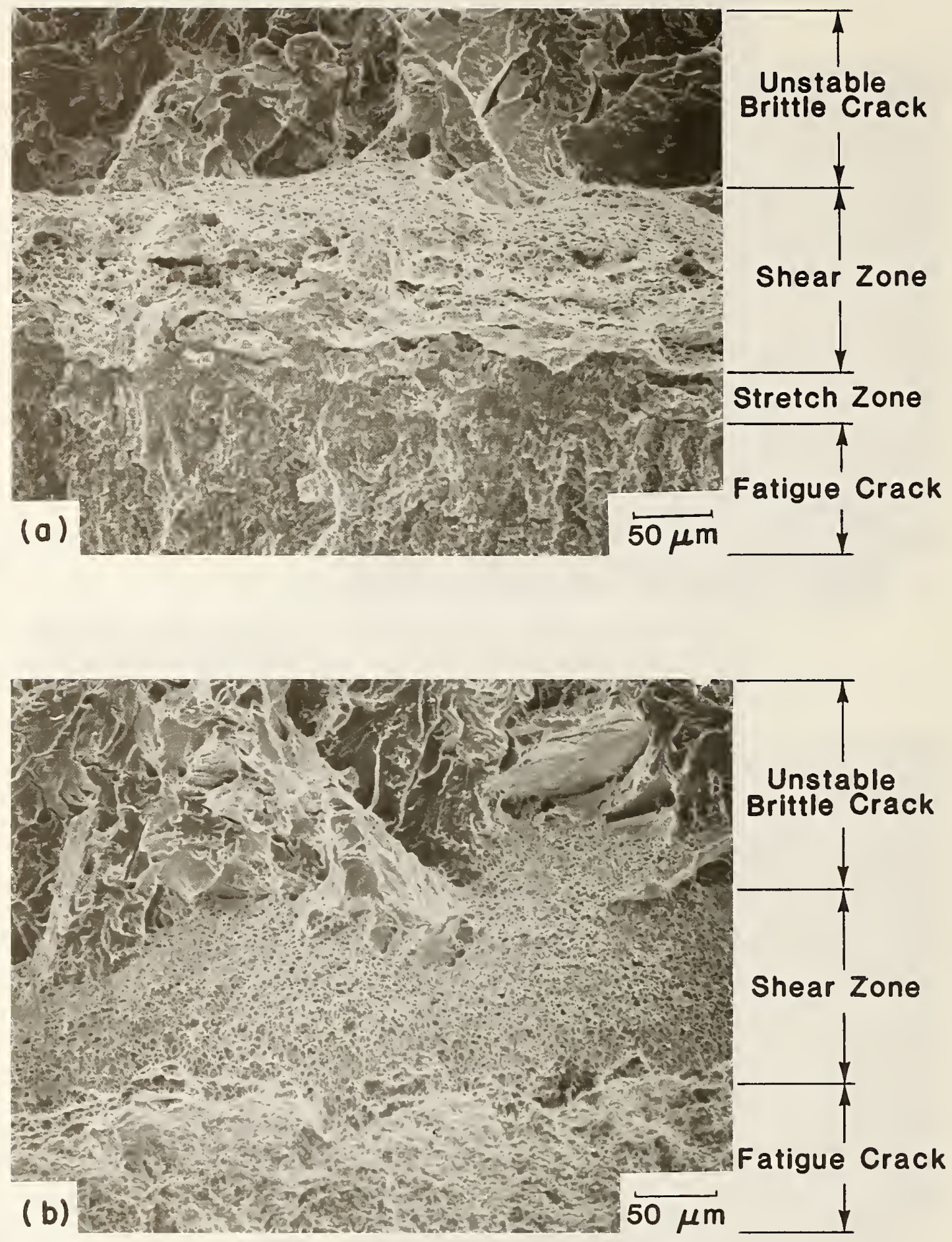

Figure 20. SEM fractographs showing the relative orientation of the stretch zone and the shear zone. (a) $0^{\circ}$ tilt (b) $-45^{\circ}$ tilt. 

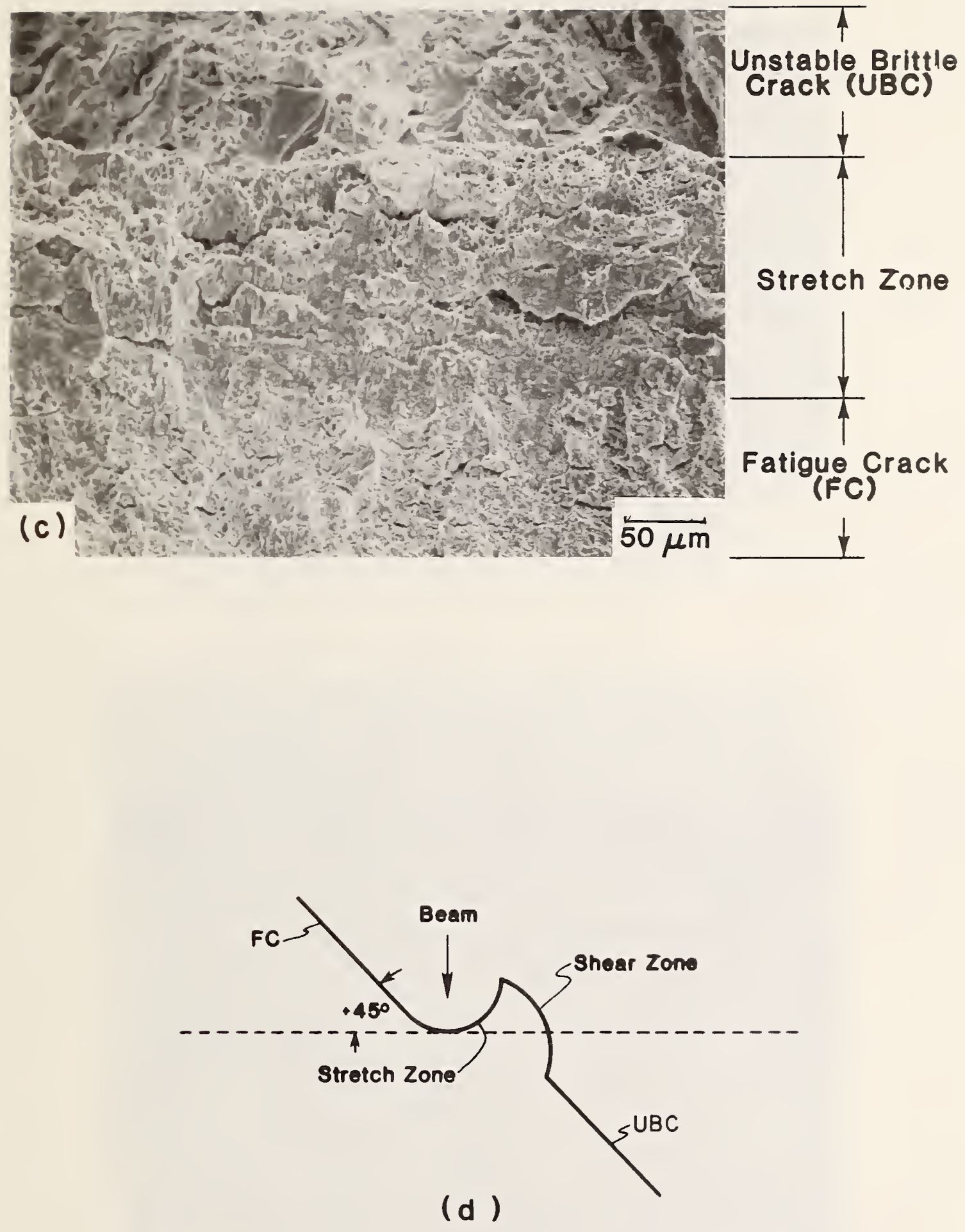

Figure 20. (continued)

(c) $+45^{\circ}$ tilt (d) A schematic showing the specimen at $+45^{\circ}$ tilt angle relative to the electron beam. 

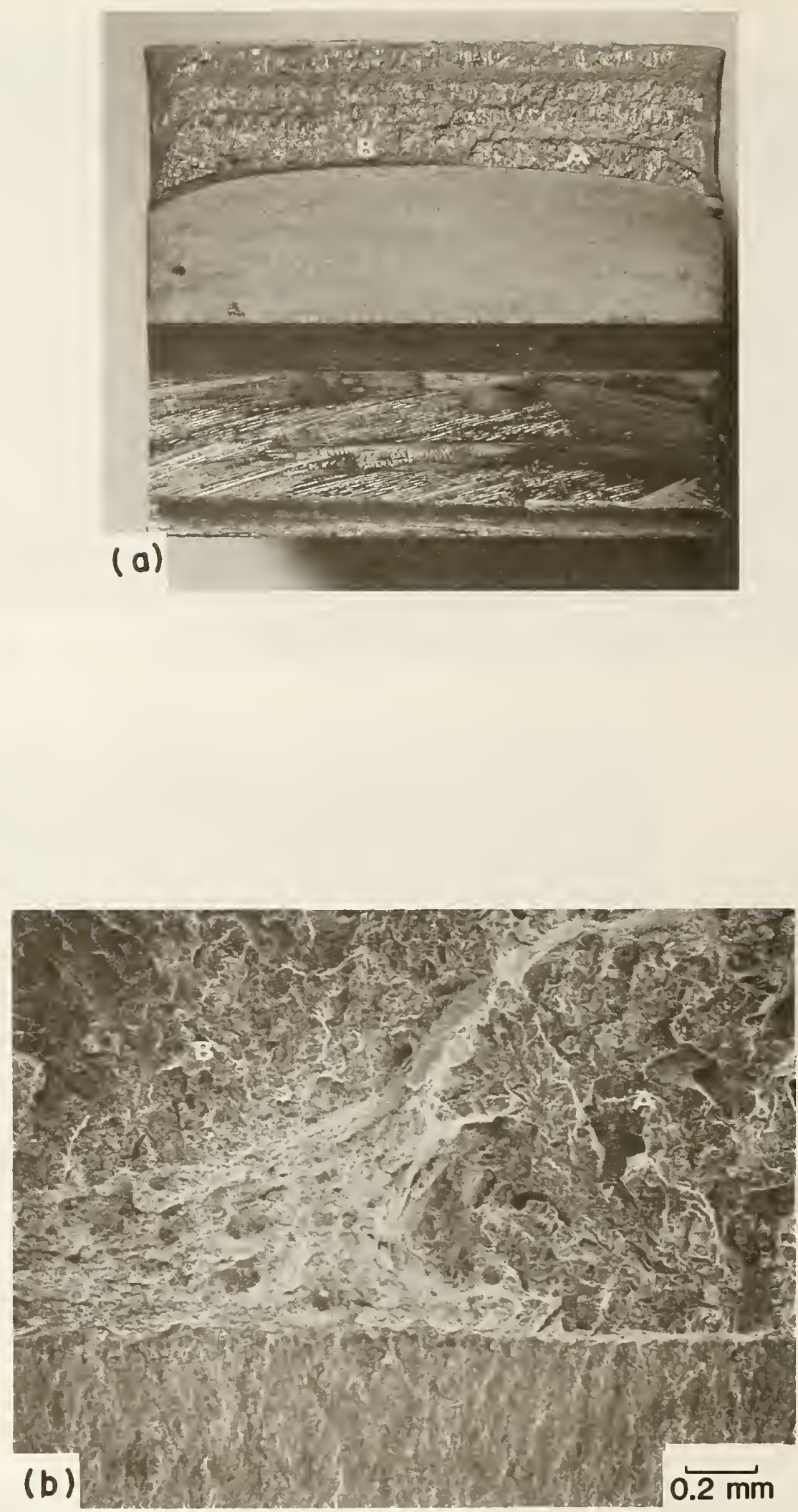

Figure 21. (a) Macrograph of the fracture surface of the SENB specimen with $\mathrm{a} / \mathrm{W}=0.75$ geometry tested at $-48^{\circ} \mathrm{C}$. (b) Low magnefication SEM fractorgraph showing the boundary between areas $A$ and $B$ as marked on the macrograph shown in (a). 

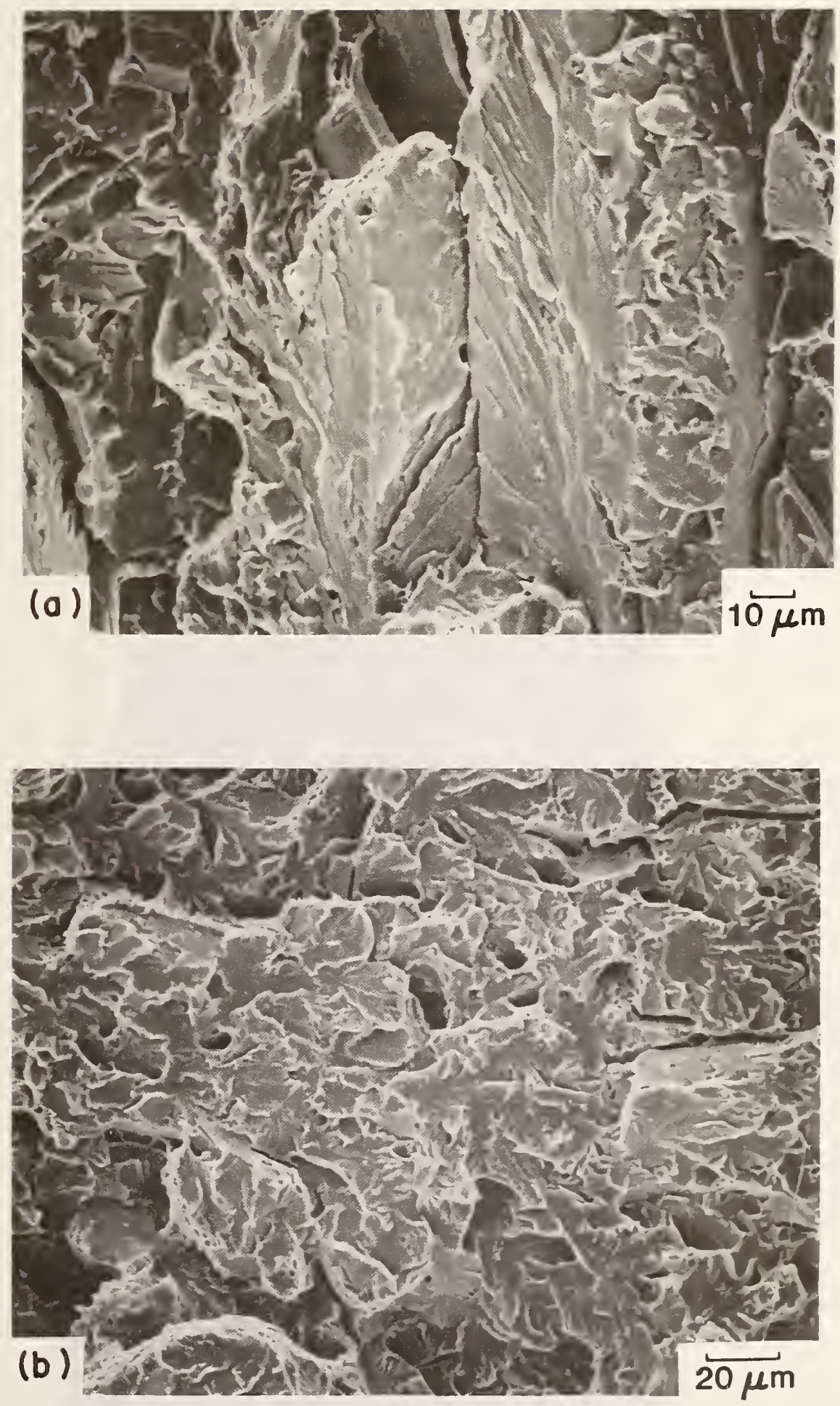

Figure 22. SEM fractograph showing the brittle fracture in areas $A$ (a) and B (b) as marked on the macrograph shown in figure 21. 


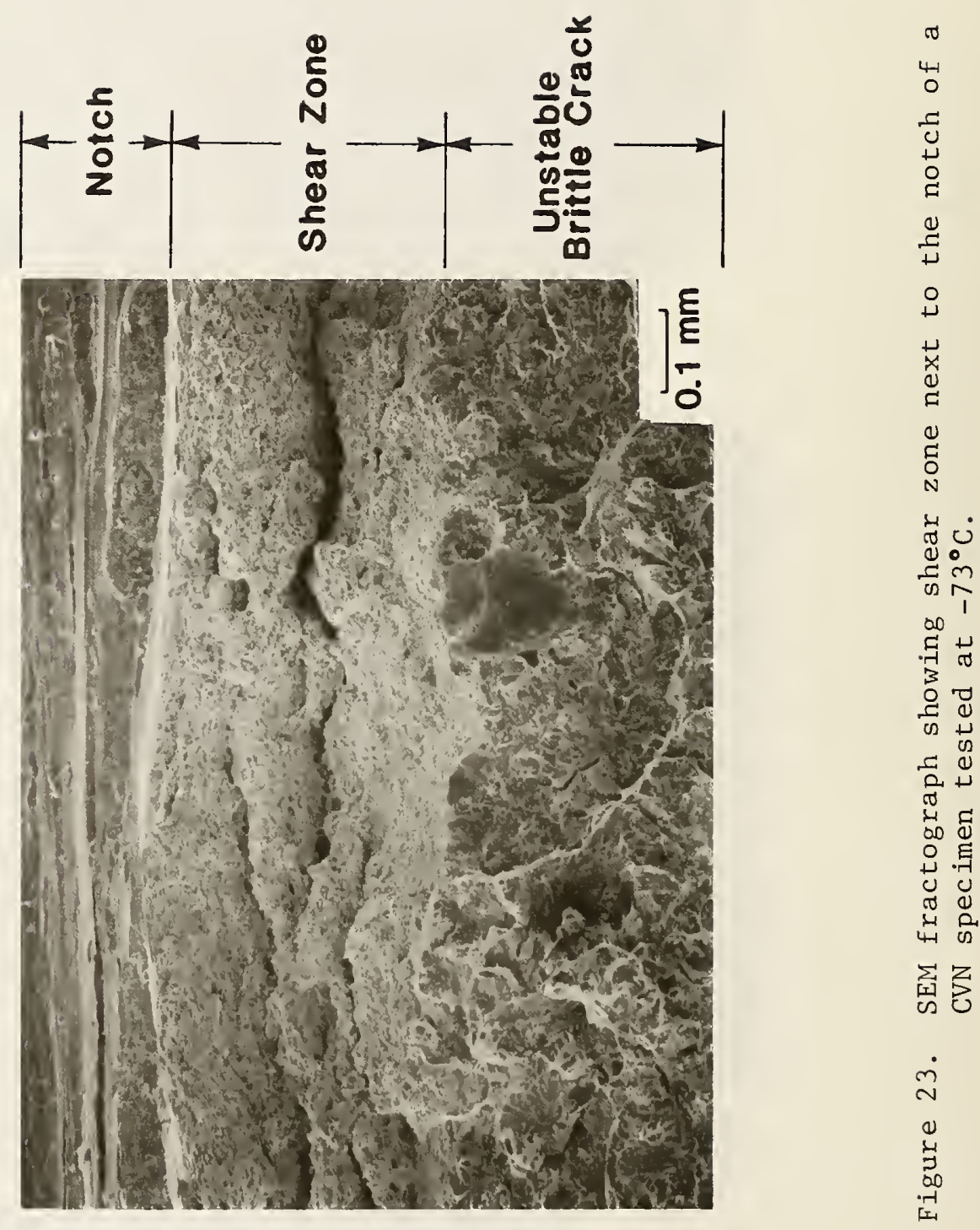




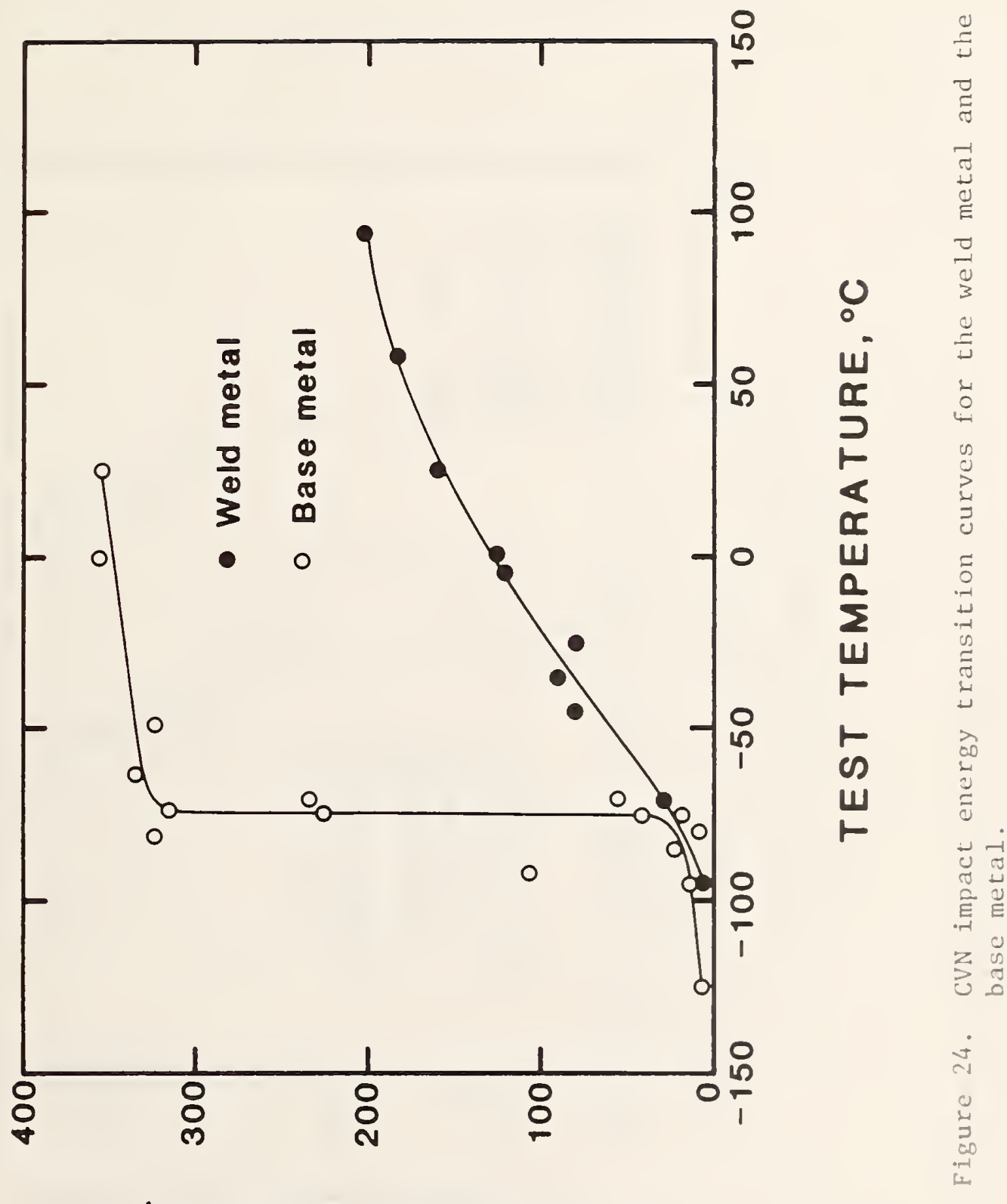

「 ‘ 


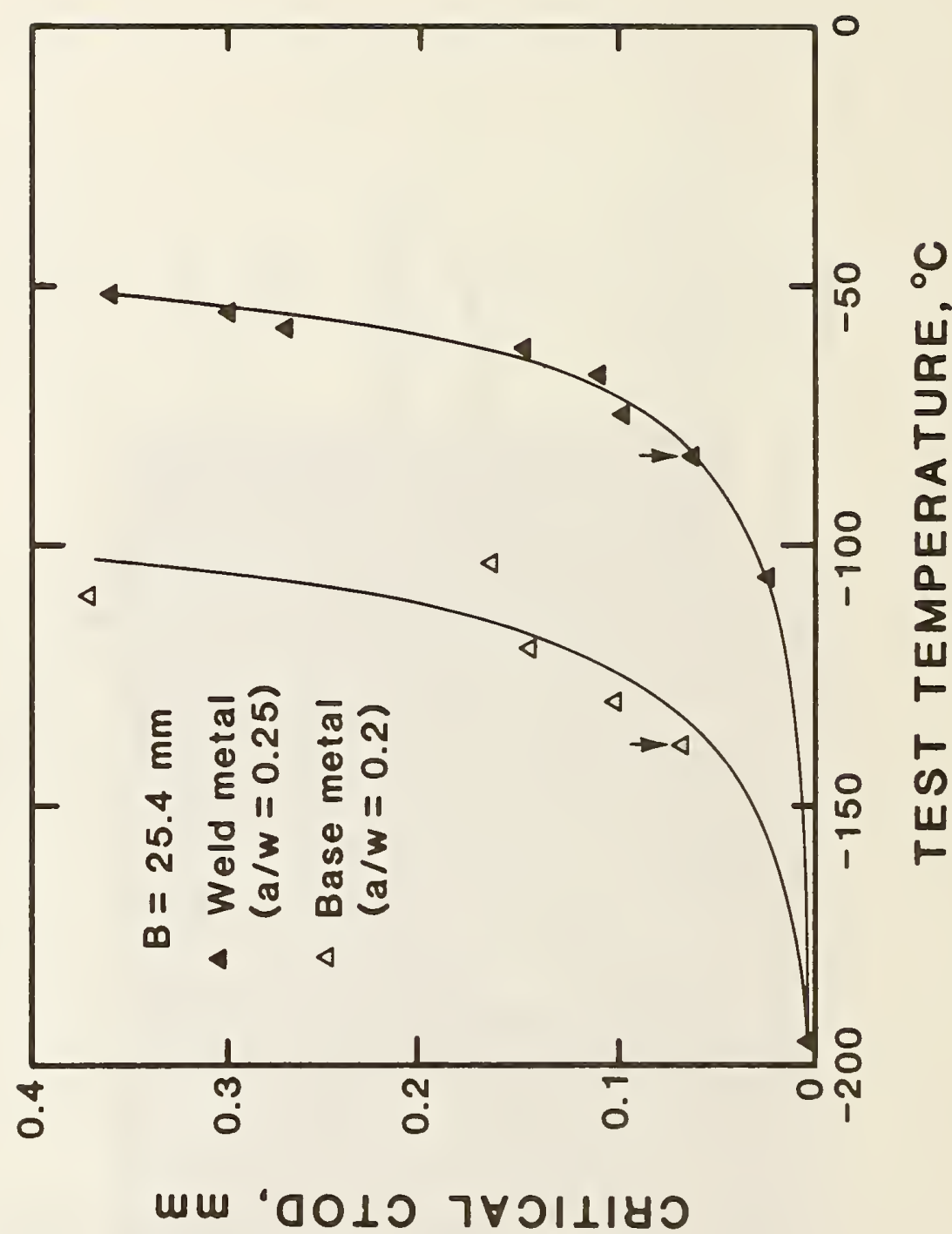

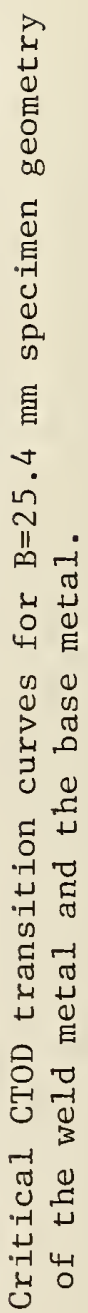

0
$v$
0
$y$
7
0
-1
$a=1$ 


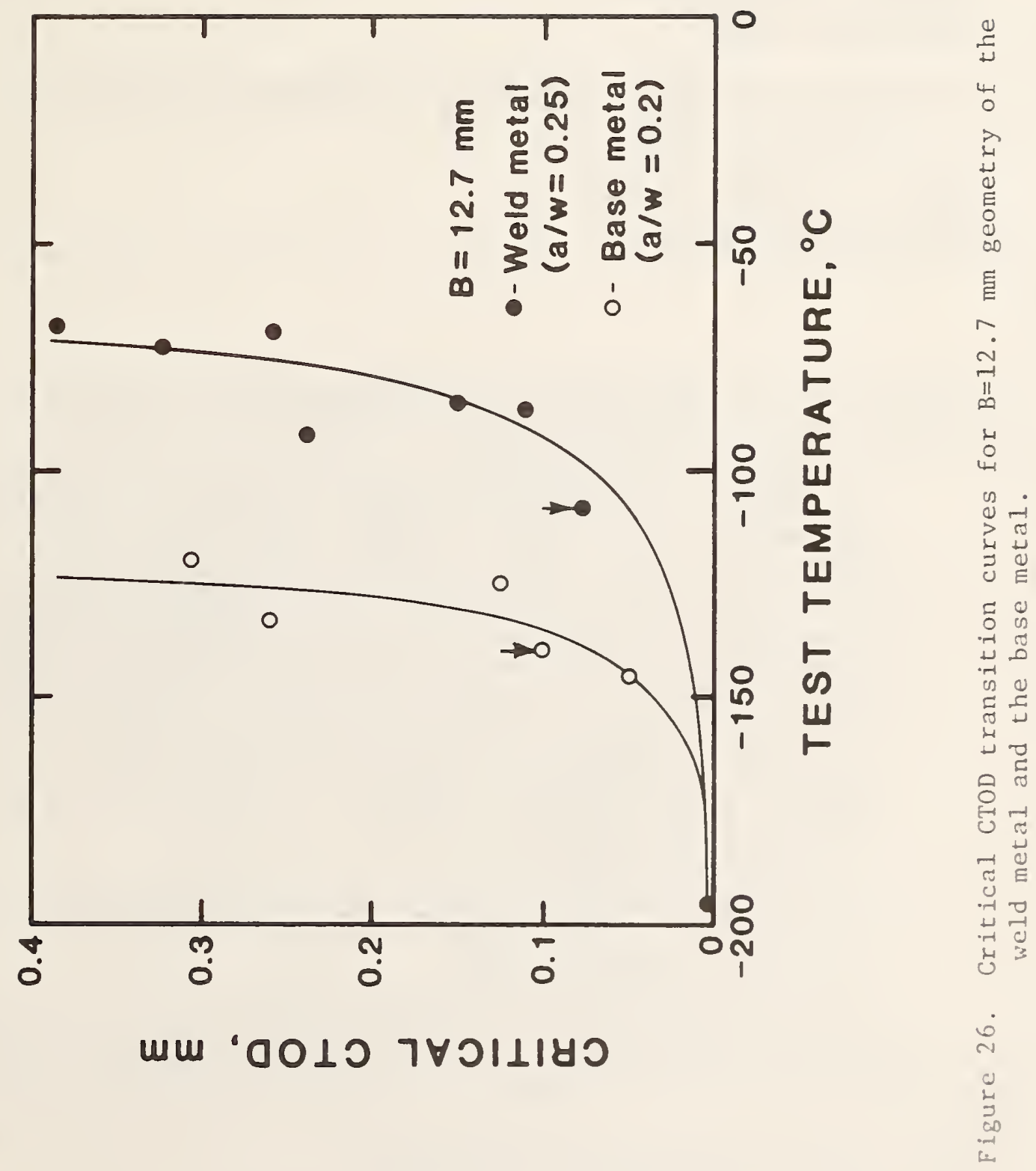


NBS-114A (REV. 2-80)

U.S. DEPT. OF COMM.

BIBLIOGRAPHIC DATA

SHEET (See instructions)

1. PUBLICATION OR REPORT NO.

NBSIR 85-3020
2. Performing Organ. Report No.

3. Publication Date

4. TITLE AND SUBTITLE

Ductile-to-Brittle Transition in Steel Weldments for Arctic Structures

5. AUTHOR(S)

F. Zia-Ebrahimi

6. PERFORMING ORGANIZATION (If joint or other than NBS, see in structions)

7. Contract/Grant No.

NATIONAL BUREAU OF STANDARDS

DEPARTMENT OF COMMERCE

WASHINGTON, D.C. 20234

8. Type of Report \& Period Covered

9. SPONSORING ORGANIZATION NAME AND COMPLETE ADDRESS (Street, City. State, ZIP)

U.S. Department of Interior

Minerals Management Service

12203 Sunrise Valley Drive

Reston, Virginia 22091

10. SUPPLEMENTARY NOTES

Document describes a computer program; SF-185, FIPS Software Summary, is attached.

11. ABSTRACT (A 200-word or less factual summary of most significant information. If document includes a significant bibliography or literature suryey. mention it here)

This report summarizes the work performed in support of the development of frac-

ture criteria for steel weldments in arctic structures. The ductile-to=brittle transition behavior of a shielded metal-arc weld, typical of steel weldments in arctic structures, has been studied. Fracture toughness, Charpy V-notch impact energy, and tensile properties have been measured as a function of temperature throughout the ductile-tobrittle transition range. The effect of geometric dimensions on fracture toughness has been studied for three geometries of single-edge-notch-bend (SENB) specimens. The fracture surfaces of broken specimens have been characterized by scanning electron microscopy (SEM). The microstructure of the multiple-pass weldment has been studied by optical microscopy. The mechanical properties of the steel weldment have been compared to the base metal, an ABS grade EH36 steel in normalized condition.

The results indicate that the resistance to brittle fracture is the same in both the base metal and the weld metal; however, the weld metal has a much lower resistance to ductile fracture than the base metal does. The high ductile-to-brittle transition temperature of the weld metal is attributed to its high tensile strength and low resistance to ductile fracture.

The ductile-to-brittle transition temperature increased by $25 \propto \mathrm{C}$ with increasing specimen thickness (from $12.7 \mathrm{~mm}$ to $25.4 \mathrm{~mm}$ ), an effect that can be attributed to both the constraint and statistical effects. The slight increase in ductile-to-brittle transition temperature with increasing crack length/specimen width ratio is discussed on the basis of constraint effects.

The SEM fractography revealed a shear zone preceding the unstable brittle fracture in SENB specimens tested in the transition temperature regime. This finding shows that tive fracture initiation process in these specimens is controlled.by ductile fracture rather than brittle fracture. although no macroscopic slow crack growth was observed.

12. KEY WORDS (Six to twelye entries; alphabetical order; capitalize only proper names: and separate key words by semicolons) crack initiation; fracture toughness; fracture surface; microstructure; 3-point band tests; transition temperature; weldments

13. AVAILABILITY

14. NO. OF

PRINTED PAGES

X. Unlimited

For Official Distribution. Do Not Release to NTIS

Order From Superintendent of Documents, U.S. Government Printing Office, Washington, D.C. 20402.

68

15. Price

X Örder From National Technical Information Service (NTIS), Springfield, VA. 22161 



